Int. J. Dev. Biol. 58: 551-562 (2014)

doi: $10.1387 / \mathrm{ijdb} .1401491 \mathrm{ln}$

\title{
Ilyanassa Notch signaling implicated in dynamic signaling between all three germ layers
}

\author{
MAEY GHARBIAH ${ }^{1}$, AYAKI NAKAMOTO ${ }^{1}$, ADAM B. JOHNSON², J. DAVID LAMBERT ${ }^{2}$ and LISA M. NAGY ${ }^{1 *}$ \\ ${ }^{1}$ Department of Molecular and Cellular Biology, University of Arizona, Tucson, Arizona, USA and \\ ${ }^{2}$ Department of Biology, University of Rochester, NY, USA
}

\begin{abstract}
Two cells (3D and 4d) in the mud snail Ilyanassa obsoleta function to induce proper cell fate. In this study, we provide support for the hypothesis that Notch signaling in Ilyanassa obsoleta functions in inductive signaling at multiple developmental stages. The expression patterns of Notch, Delta and Suppressor of Hairless $(\mathrm{SuH})$ are consistent with a function for Notch signaling in endoderm formation, the function of $3 \mathrm{D} / 4 \mathrm{~d}$ and the sublineages of $4 \mathrm{~d}$. Veligers treated with DAPT show a range of defects that include a loss of endodermal structures, and varying degrees of loss of targets of $4 \mathrm{~d}$ inductive signaling. Veligers that result from injection of Ilyanassa Delta siRNAi in general mimic the defects observed in the DAPT treated larvae. The most severe DAPT phenotypes mimic early ablations of $4 d$. However, the early specification of $4 d$ itself appears normal and MAPK activation in both $3 \mathrm{D} / 4 \mathrm{~d}$ and the micromeres, which are known to activate MAPK as a result of $3 \mathrm{D} / 4 \mathrm{~d}$ induction, are normal in DAPT treated larvae. Treating larvae at successively later timepoints with DAPT suggests that Notch/Delta signaling is not only required during early $4 \mathrm{~d}$ inductive signaling, but during subsequent stages of cell fate determination as well. Based on our results, combined with previous reports implicating the endoderm in maintaining induced fate specification in Ilyanassa, we propose a speculative model that Notch signaling is required to specify endoderm fates and $\mathbf{4 d}$ sublineages, as well as to maintain cell fates induced by $\mathbf{4 d}$.
\end{abstract}

KEY WORDS: Notch, Delta, mollusc, endoderm, $4 d$

\section{Introduction}

In most metazoan animals, establishing cell fates along embryonic axes involves an interplay between asymmetric inheritance and cell signaling. By contrast, specification of the dorsal-ventral axis in Ilyanassa obsoleta embryos has long been believed to rely solely on the inheritance of determinants relayed through an early anucleate cytoplasmic protrusion, the polar lobe, to a dorsal lineage of cells (Fig. 1). Loss of the polar lobe, or the D cell that inherits the contents of the polar lobe results in a loss of cell fates along the embryonic axes. Morphological structures such as eyes, foot, statocysts, operculum, retractor muscle, intestine, heart, larval bud cells, and shell are lost (Atkinson, 1969; Clement, 1952). However, cell signaling events required for polar lobe dependent axial specification have now been identified, overturning the assumption of autonomous activation of the polar lobe determinants.

At least four signaling events are required to induce cell fate specification along the dorsal-ventral axis. First, micromeres formed at third and fourth cleavage activate the inductive abilities of the dorsal founding cell, the D macromere (Wandelt et al., submitted; see Fig. 1 for nomenclature and Fig. 11 for a model of the early signaling events required for cell fate determination). Secondly, the activated D macromere (3D) induces proper cell fates along the dorsal-ventral axis in the micromeres formed after fifth cleavage (Clement, 1962; Fig. 11). Thirdly, the daughter cell of D macromere in the next cleavage cycle, $4 \mathrm{~d}$, completes the induction of cell fates of the other micromeres along the dorsal-ventral axis (Rabinowitz et al., 2008; Fig. 11). Fourthly, the endoderm (3ABCD) maintains induced micromere cell fates for several hours after the completion of inductive signaling (Cather, 1967; Fig. 11).

Disruption of any of these four signaling events has severe consequences on axial patterning and cell fate specification (see Fig. 11). Loss of the activating micromeres prior to fifth cleavage (Wandelt et al., submitted) or the D macromere prior to inductive

Abbreviations used in this paper: DAPT, (N-[N-(3,5-Difluorophenacetyl-L-alanyl)]-Sphenylglycine t-Butyl EsterDl, Delta; N, Notch; N-ICD, Notch's cleaved intracellular domain; SuH, Suppressor of Hairless.

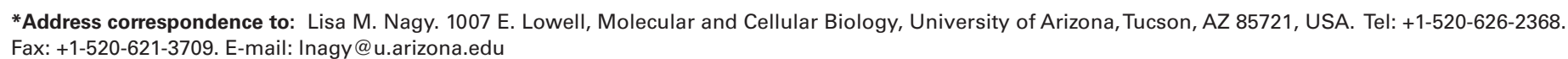

Accepted: 18 September 2014.

ISSN: Online 1696-3547, Print 0214-6282 
A
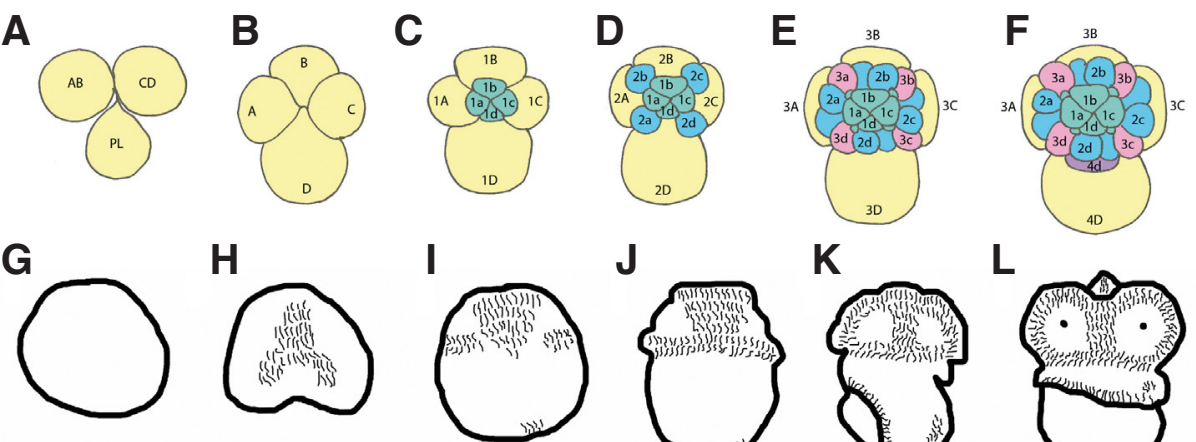

M

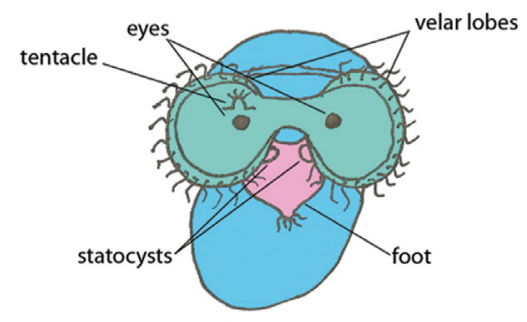

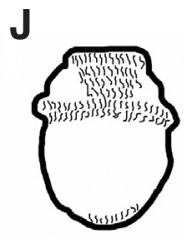

K

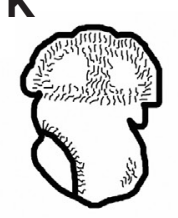

$\mathbf{L}$
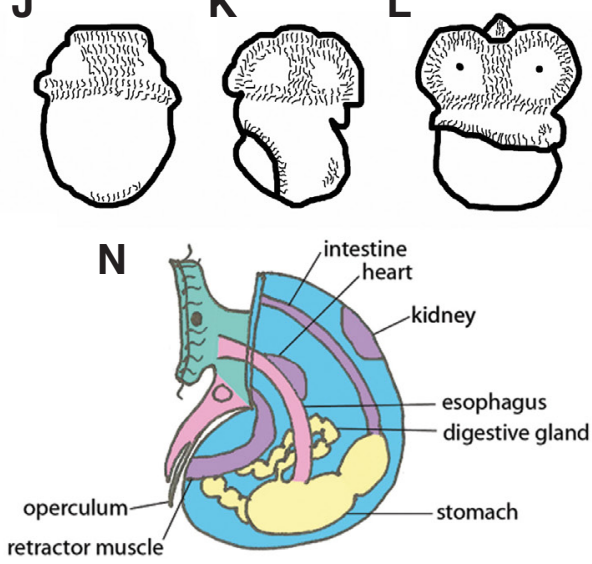

Fig. 1. Developmental stages and fate map of Ilyanassa obsoleta. A-F are cleavage stage embryos. (A) During first division, an anucleate sac of cytoplasm called the polar lobe (PL) is extruded. (B) During second cleavage, four macromeres $(A B C D$; yellow) are formed and the $D$ cell is much larger due to exclusive inheritance of the polar lobe material. (C) The macromeres divide toward the animal pole in a synchronous manner to form much smaller cells called the first quartet micromeres (1abcd; teal). (D) The macromeres divide again to from the second quartet cells (2abcd; blue). (E) The macromeres divide again to from the third quartet cells (3abcd; pink) and the second quartet cells divide (blue). (F) The 3D macromere divides much earlier than the other third order macromeres to form its daughter micromere, $4 d$ (purple). G-L are post-cleavage stage larvae. (G) Larva at the end of the first day of development after the completion of epiboly. (H) Larva at the end of the second day of development after gastrulation has begun. Apical cilia have begun to differentiate. (I) Larva at the end of the third day of development, organogenesis is ongoing. (J) Larva at the end of the fourth day of development. (K) Larva at the end of the fifth day of development. (L) Larva at the end of the sixth day of development after the completion of organogenesis. This is the fully developed veliger. (M,N) Veligers with generalized clonal contributions with color-coding that matches cells in Fig. 1F. Generally, first quartet cells give rise to the velum (teal), second quartet cells give rise to the shell (blue), third quartet cells give rise to the esophagus and foot (pink), $4 d$ gives rise to the intestine, heart, kidney, and retractor muscle (purple), and 3ABC/4D give rise to the endoderm and nutritive yolk (yellow) (Render, 1991; Render, 1997).

signaling during fifth cleavage, mimics the phenotypic consequences of polar lobe loss (Clement, 1962). Loss of 4d prior to the completion of its induction of micromere cell fates results in veligers with reduced velum, foot, shell and absentor disorganized endoderm as well as its direct mesendodermal derivatives (heart, intestine, and kidney; Rabinowitz et al., 2008). Loss of the endoderm (3ABCD) several hours after the completion of induction results in a failure to specify cell fates along the embryonic axes in a manner that mimics polar lobe ablation, early micromere ablations or early $D$ macromere ablations (Cather, 1967).

With few exceptions, the molecular nature of these signaling events is not well characterized. One exception is the activation of MAPK in the 3D macromere as a result of cell contact dependent activation by the micromeres. MAPK is a critical component of the signal transduced through direct cell contact between the 3D macromere and the micromeres required for proper cell fate specification in the micromeres (Lambert and Nagy, 2001; Wandelt et al., submitted). Loss of the polar lobe results in a failure to properly activate MAPK in the 3D macromere and the induced micromeres (Lambert and Nagy, 2001). However, inactivated MAPK is abundant in all macromeres and the micromere signal selectively activates the inductive ability of the 3D cell and the MAPK in this macromere (Oberg et al., in prep.). MAPK activation in 3D is likely not sufficient to explain the inductive capacity of that cell, as embryos that fail to activate MAPK in 3D can still properly activate MAPK in the micromeres (Wandelt et al., submitted). These data suggest that multiple, independent signaling cascades are involved in the induction of cell fates by 3D/4d. Thus, any candidate search for signaling pathways involved in axial patterning in I/yanassa should not be restricted to signals that inhibit MAPK activation in 3D. Signals that have no effect on MAPK activation in $3 \mathrm{D}$, yet still result in axial patterning defects should also be considered.
The Notch $(\mathrm{N})$ signaling pathway fits several known requirements for the activation signal of the llyanassa dorsal cell lineage. $\mathrm{N}$ signaling requires cell-cell contact (Fiuza and Arias, 2007) and cell-cell contact is required for dorsal cell lineage activation and for induction of nearby cells by the dorsal cell lineage (Sweet, 1996; Wandelt, 2005). N signaling has also been implicated in mesendodermal specification (Sherwood and McClay, 1997; Sherwood and McClay, 2001; Sweet et al., 2002). The daughter cell (4d) of the initial inducing cell (3D) both completes dorsal induction of micromere cell fates (Rabinowitz et al., 2008) and gives rise to mesendodermal organs (Clement, 1986b; Render, 1997). Thus, N signaling is an excellent candidate to function in this early inductive patterning event.

$\mathrm{N}$ is a single pass transmembrane receptor protein and signaling is transduced subsequent to the binding of one its ligands. Canonical $\mathrm{N}$ ligands are also single pass transmembrane proteins and are members of the DSL (Delta/Serrate/lag-2) family of proteins. Signal transduction is achieved by the release of the intracellular portion of the $\mathrm{N}$ receptor via $\gamma$-secretase proteolysis upon ligand binding (reviewed in Lai, 2004; Fiuza and Arias, 2007). The cleaved intracellular domain (N-ICD) translocates into the nucleus and associates with a DNA binding protein CSL (for human, CBF1;Drosophila, Suppressor of Hairless; C. elegans, lag-1) and other transcriptional regulators to regulate transcription of $\mathrm{N}$ target genes (Bray 2006; Artavanis-Tsakonas et al., 1999; Kadesch 2004). In the absence of $\mathrm{N}-\mathrm{ICD}, \mathrm{CSL}$ acts with other co-repressors to suppress $\mathrm{N}$ target gene transcription (Bray, 2006; Kopan and llagan, 2009). This canonical $\mathrm{N}$ pathway is conserved across species (Artavanis-Tsakonas et al., 1999; Bray, 2006; Kopan and llagan, 2009). This explanation of the most basic properties of $\mathrm{N}$ signaling does not convey the complex mechanisms that regulate N-DI signaling (see recent reviews by Dominquez, 2014; Hori et al., 2013). To what degree 
the complexity of this regulation is conserved across species is not known. Here we report our initial investigation into the basic $\mathrm{N}-\mathrm{DI}$ pathway in Ilyanassa.

To test the role of $\mathrm{N}$ signaling in Ilyanassa, we cloned and characterized the expression patterns of the mRNAs encoding the $\mathrm{N}$ receptor, one of its ligands Delta (DI) and one of the downstream effectors in the canonical N pathway, Suppressor of Hairless, (SuH). To test the function of N-DI signaling, we took advantage of the fact that cleavage of $N$ by $\gamma$-secretase can be inhibited with the pharmacological inhibitor N-S-phenyl-glycine-t-butyl ester (DAPT): the intracellular domain of Notch does not move to the nucleus, and thus, the Notch pathway is blocked. While DAPT is known to also inhibit the cleavage of the Delta (LaVoie and Selkoe, 2003), DAPT treatment is frequently used to block $\mathrm{N}$ signaling in many different systems and is known to phenocopy disruption of $\mathrm{N}$ function produced through mutation or RNAi (Geling et al., 2002; Micchelli et al., 2003; Chen et al., 2006; Fujimaki et al., 2006; Gal et al., 2006; Kitzmann et al., 2006; Li et al., 2006; Zecchin et al., 2006; Pueyo et al., 2008; Munder et al., 2013). We used both DAPT treatment and IODI siRNA to test the consequences of disrupting $\mathrm{N}$ signaling. DAPT treatment results in veligers with abnormal development of endoderm derived organs, reduced velum and foot, and variable shell defects. The most severely affected veligers suggest a loss of endoderm, and a loss cell fates that depend on 3D/4d signaling. Using activated MAPK in $3 \mathrm{D}$ and the micromeres as a marker of dorsal lineage induction, we found that DAPT treatment has no consequence on MAPK activation in 3D or in the micromeres that require fate induction. DAPT treatment also has no consequence on early $4 d$ division, early $4 d$ specification, or the formation of the larval buds, $4 d$ clonal derivatives. By treating with DAPT at successively later time points, we found DAPT sensitive periods later in development, suggesting that $\mathrm{ION}$ signaling may be required to maintain $4 d$ induced cell fates or that a subset of $4 d$ derivatives are lost. We speculate that IoN-DI signaling has an early function to specify the endoderm, and a later function in which loN-dependent signaling from the endoderm maintains induced fates in the micromeres and the clonal descendants of $4 \mathrm{~d}$.

\section{Results}

\section{Identification and expression of Ilyanassa N, DI and Suppres- sor of Hairless orthologs}

Partial sequences of IoN (1196bp and 689bp non-overlapping fragments to N-ECD and N-ICD), IoDI (314bp) and IoSuH (1350bp), key members of the canonical $\mathrm{N}$ signaling pathway, were identified using degenerate PCR and screening of the Ilyanassa EST database (Kingsley et al., 2007). The predicted amino acid sequences of a portion of these clones aligned with their orthologous sequences in Mus musculus, Drosophila melanogaster, and Lottia gigantea are shown in Fig. 2. No additional orthologs of these genes were found either through degenerate PCR or searching the ESTs, although additional components of the $\mathrm{N}$ signaling pathway were identified and will be reported elsewhere.

We examined the expression of the Ilyanassa orthologs of $\mathrm{N}$, $\mathrm{DI}$ and SuH during early cleavage stages (Fig. 3). Transcripts from all three genes show widespread expression, but with variation in patterns of subcellular localization and intensity of expression. All undergo dynamic changes in intracellular localization, showing either diffuse cytoplasmic, centrosomal, or perinuclear expression at different cleavage cycles (eg. compare Fig. 3G to 3I). During the $2 \mathrm{q}$ stage, loSuH transcripts show an interesting enhanced perinuclear expression in the macromeres $2 \mathrm{C}$ and $2 \mathrm{D}$, particularly in 2D (Fig. 3G). Both IoDI and IoSuH expression are stronger in dorsal lineage cells after the birth of $4 d$ (Fig. 3F, 3I).

We also examined the expression of the llyanassa orthologs of $\mathrm{N}$, DI and SuH during the first few divisions of the $4 \mathrm{~d}$ lineage using in situ hybridization. IoN is expressed ubiquitously during these stages (Fig. 4A). After $4 \mathrm{~d}$ divides, around the 45 cell stage, loDI is strongly expressed in the $4 \mathrm{~d}$ daughters $4 \mathrm{dL}$ and $4 \mathrm{dR}$, as well as $3 \mathrm{c}$ and $3 d$ derivatives. It is more weakly expressed in the $3 a^{1}$ and $3 b^{1}$ cells, and on the centrosomes in 3A, 3B and 3C (Fig. 4B). IoSuH

A

Notch

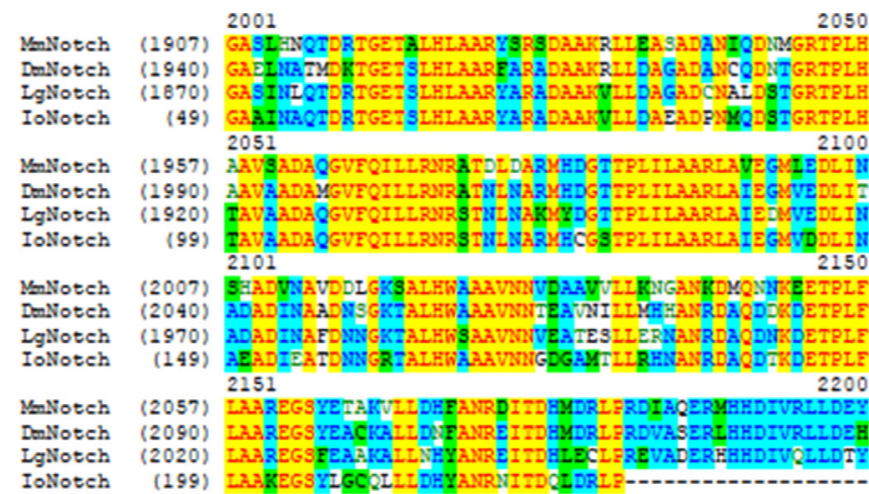

B

\section{Delta}

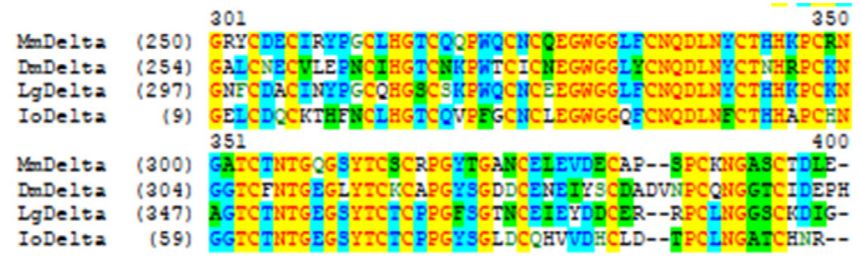

C

\section{Suppressor of Hairless}

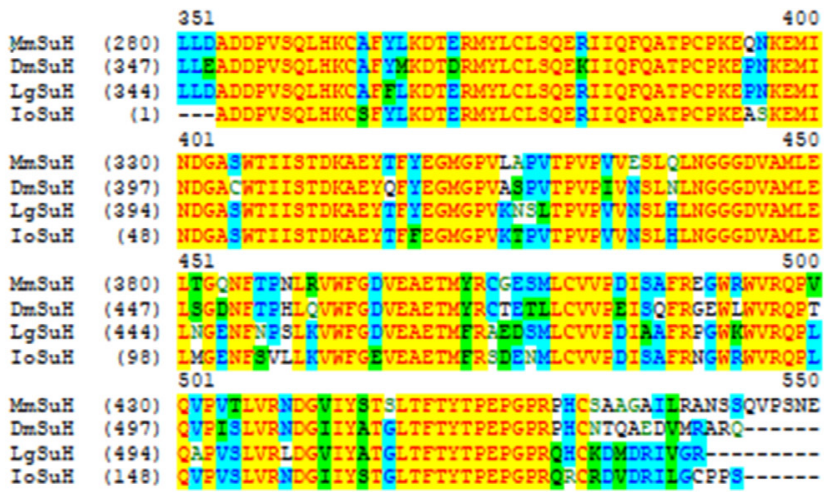

Fig. 2. Sequence alignments of partial predicted amino acid sequences of $I o N, I o D I$ and $I o S u H$. The predicted amino acid sequences of portions of the identified loN pathway members, (A) loN, (B) loDI and (C) loSuH are shown aligned with orthologous sequences from $\mathrm{Mm}$, Mus musculus; Dm, Drosophila melanogaster; and Lg, Lottia gigantea obtained from the NCBI database. The color coding is the standard amino acid coloring scheme used in Clustal. 

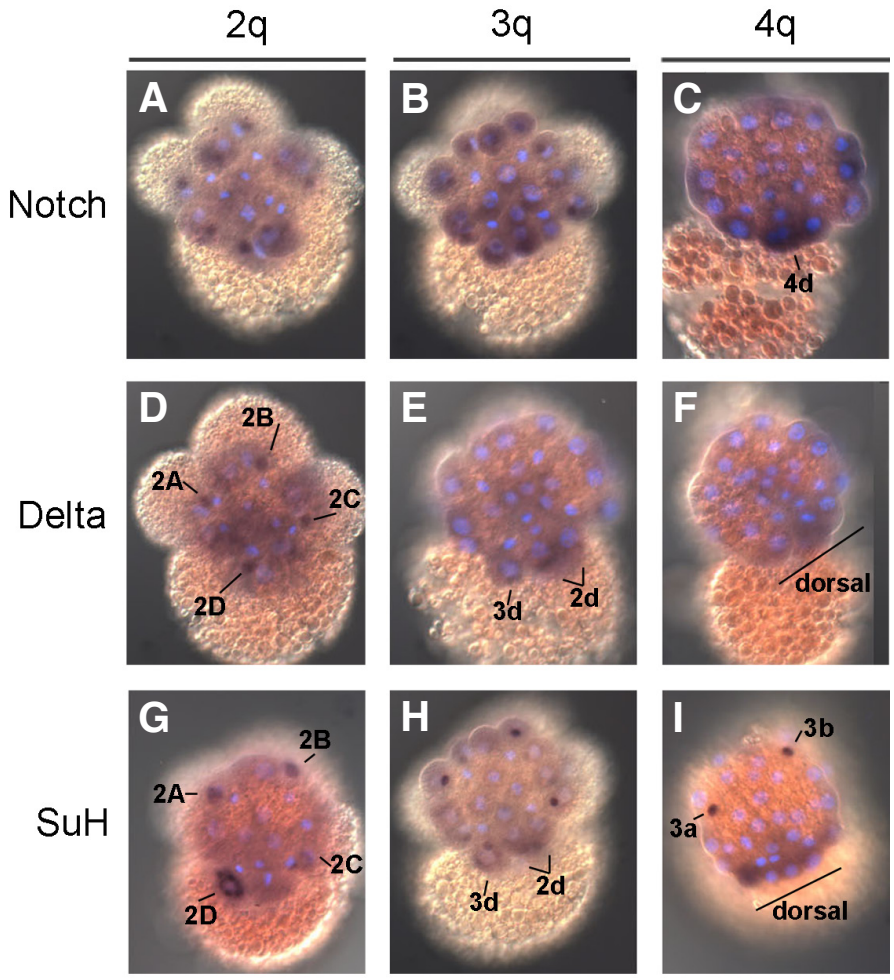
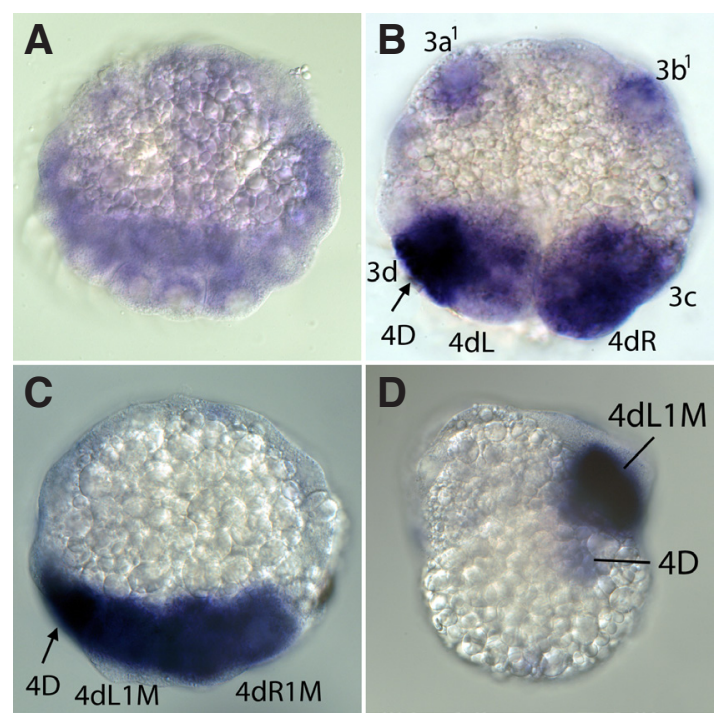

Fig. 3 (Left). Expression of IoN-DI pathway components during the early cleavage stages. (A) loN: At the $2 q$ stage, all cells in the embryo have a low level of cytoplasmic expression. 2 q cells have slightly stronger cytoplasmic expression. All cells in the embryo, with the exception of 19 cells, have centrosomal localization. (B) At the early $3 q$ stage, all cells in the embryo have cytoplasmic expression. All cells with the exception of $1 q$ cell have centrosomal localization. $2 d$ and $3 d$ cells have slightly stronger expression than all other cells. (C) After the birth of $4 d$, all cells in the embryo have a low level of cytoplasmic expression. All cells have lost their centrosomal localization. 2q cells have slightly stronger diffuse expression. $3 d$ and $4 d$ also have strong diffuse expression. (D) loDl expression: at the 2q stage, low level cytoplasmic staining is observed in all cells of the embryo. Abundant centrosomal localization is observed in the macromeres (2ABCD). (E) At the 3q stage, all cells of the embryo have a low level of cytoplasmic staining. Less abundant centrosomal staining is observed in 3abc. Strong cytoplasmic expression is observed in $2 d$ and $3 d$. (F) After the birth of $4 d$, low level cytoplasmic staining is observed in all cells of the embryo with strong expression in the dorsal lineage cells. (G) loSuH: at the $2 q$ stage, low level cytoplasmic staining is observed in all cells of the embryo. Centrosomal expression is observed in $3 \mathrm{~A}$ and $3 B$ macromeres. Perinuclear staining is observed in $3 C$ and $3 D$ macromeres with much more abundant expression in $3 D$. Less abundant centrosomal staining is observed in the micromeres. More abundant cytoplasmic staining is observed in $2 d$. (H) At the 3q stage, low level cytoplasmic staining is observed in all cells of the embryo. Centrosomal staining is observed in all cells of the embryo except for the macromeres and the 1q cells. Strong cytoplasmic staining is observed in $2 d$ and 3d. (I) After the birth of 4 d, low level cytoplasmic staining is observed in all cells of the embryo. Centrosomal staining is observed in 3a and 3b. Strong cytoplasmic staining is observed in the $D$ lineage cells.

Fig. 4 (Right). Expression of IoN-DI pathway components during early 4d lineage proliferation by RNA in situ hybridization. Views in A-C are of the animal pole with dorsal (D quadrant) down. (A) loN expression around the 54 cell stage, when the $4 d$ lineage consists of $4 d L$ and $4 d R$. Expression is ubiquitous, the stronger expression on the dorsal side is likely due to the higher number of cells present there because of the $4 d$ lineage. (B) loDI After $4 d$ divides, around the 45 cell stage, IoDl is strongly expressed in the $4 d$ daughters $4 d L$ and $4 d R$, as well as $3 c$ and $3 d$ derivatives. It is more weakly expressed in the $3 a^{1}$ and $3 b^{1}$ cells, and on the centrosomes in $3 A, 3 B$ and $3 C$. (C) At the 59 cell stage, loSuH is expressed in the mesoteloblasts $4 d L 1 M$ and $4 d R 1 M$. It is also in $4 D$, which underlies $3 d^{1}$ and $3 d^{2}$, giving the appearance of expression in those cells. (D) Embryo at the same stage as in (C) viewed from the left side with the animal pole up and the dorsal side to the right, showing staining in $4 d L \& R 1 M$ cells but not in the overlying micromeres.

is also largely restricted to the $4 \mathrm{~d}$ lineage (Fig. 4C). At the 54 cell stage, the transcript is strongly expressed in the bilaterally paired teloblast cells $4 \mathrm{dL} 1 \mathrm{M}$ and $4 \mathrm{dR} 1 \mathrm{M}$ (Fig. 4D). It is also abundant near the nucleus of the 4D cell. This cell only contributes to cells of unknown function within the digestive lumen and is not required for normal morphogenesis (Clement, 1962; Render, 1997). These expression patterns are all within the first 10 hours of development (see Goulding, 2009 for a precise and elegant timetable of early Ilyanassa development), the expression patterns of IoN/D/SuH beyond the first day of development are not reported here.

\section{Embryonic inhibition of $\mathbf{N}$ signaling results in a range of veliger defects}

To determine the effects of DAPT on early embryonic devel- opment, embryos were continuously incubated in 25uM DAPT from one cell to 150 minutes after the birth of the third quartet of micromeres $(3 q+150)$. This incubation period encompasses the period when $3 \mathrm{D}$ is induced to become the embryonic organizer, and $3 D / 4 d$ induce specific cell fates in the micromeres. After this time the embryos were washed from the drug, and DAPT treated and control embryos were cultured to veliger stage (7 days, RT) and scored for defects. The most severely affected DAPT treated veligers had a striking phenotype, and in general appeared as "floating heads" that swam in circles to the right when viewed in their sea water dishes (Fig. 5F, 10D). In general, DAPT treated veligers had differentiated head tissue but significantly reduced or absent shell. In many of these veligers the internal organs were reduced to a yolky mass with no distinguishable features. A bi-lobed velum 
and foot were present, but were frequently reduced in size. Eyes and statocysts were present. The esophagus was present but typically stunted. Intestines were present, but typically abnormally positioned. The distinguishing physical characteristics of other endodermally derived organs- stomach, digestive glands, and style sacs could not be conclusively scored in the small mass of internal tissue at the base of the head, but were either abnormally formed or missing. Other structures that derive from $4 d-$ larval retractor muscle and hearts were not scored. Thus, veligers displayed a range of defects including abnormally formed endoderm and structures that depend on 3D/4d induction - reduced velum, reduced foot, small or no shell formation. Thus, inhibition of $\mathrm{N}$ signaling affects endoderm formation and many of the cell fates induced by $3 \mathrm{D} / 4 \mathrm{~d}$, as well as the $4 \mathrm{~d}$ mesendodermal lineage.

To further evaluate our results, we grouped the veligers resulting from DAPT treatment into the following four categories (Fig. 10). 1) "Normal" - This category included embryos that had a small retraction of the internal organs from the shell that is sometimes observed in normal development; 2) "Least" - veligers typically displayed normal shell, velum and foot development. Endodermally derived internal organ formation was severely affected. Internal organs were either missing or condensed at base of head within the shell. $20 \%$ of these veligers had minor abnormalities associated with more anterior structures, including velum, foot, eyes, operculum; 3) "Intermediate" - veligers that display reduced shell, velum and foot development and absent or severely disrupted internal organ formation. $93 \%$ or more of these veligers had abnormalities associated with more anterior structures; 4) "Severe" - veligers which display reduced velum and foot, absent or extremely rudimentary shell formation, and absent or severely disrupted internal organ formation. All of these veligers had varying degrees of abnormalities associated with the head.

Categorization of the resulting phenotypes was based predominantly on the effect on the shell. All affected veligers had obvious defects in endodermally derived organs, and within each category these defects ranged from the internal organs appearing either condensed or poorly separated within the shell, or missing entirely, with only yolk visible. The degree to which the most anterior structures, the velum and associated head structures, were affected was also variable within each category. In many cases the head appeared normal, but abnormalities in the head appeared with an increasing frequency as the overall severity of the phenotype increased. It is unlikely that these severely affected

Fig. 5. N signaling inhibition with DAPT has no consequence on MAPK activation but does have significant effects on morphogenesis. (A-D1) Antibody staining against phosphorylated MAPK. (A1) 3D MAPK activation in DMSO controls at 3q+30 minutes (side view). (B1) 3D MAPK activation in embryos treated with DAPT from one cell stage to $3 q+30$ minutes (side view). (C1) MAPK activation in micromeres in DMSO controls at 3q+150 minutes (top view). (D1) MAPK activation in micromeres in embryos treated with DAPT from one cell stage to $3 q+150$ minutes (top view). (A-D2) Phalloidin staining of embryos pictured in A-D1. (A-D3) Merged images of both MAPK activation and phalloidin staining. (E) DMSO control veliger grown to day 9 (side view). (F) DAPT treated veliger (from one cell to $3 q+150$ minutes) grown to day 9. (G) Table summarizing the data comparing DMSO and DAPT animals. Animals were scored during cleavage for MAPK activation and during veliger stage for phenotype. e, eye; g, gut; op, operculum; sh, shell; ve, velum. larvae arise from a general toxic effects of DAPT because early markers of cell fate specification were normal (see below, Fig. 7), and embryos treated at late stages of development developed normally (see Fig. 10F).

\section{$N$ signaling is not required for MAPK activation in $3 D$ or induced micromeres}

Given the dramatic effect of DAPT treatment during the early cleavage stages, we asked whether $\mathrm{N}$ signaling functions in specification of the 3D organizer. To do this, we examined the pattern of MAPK activation after DAPT treatment. In untreated embryos, MAPK is activated in 3D shortly after the birth of the third quartet (3q+30 minutes) serves as a marker of $3 D$ induction (Lambert and Nagy, 2001; Fig. 5 A1-A3). After MAPK activation in $3 D$, select micromeres that require induction activate MAPK
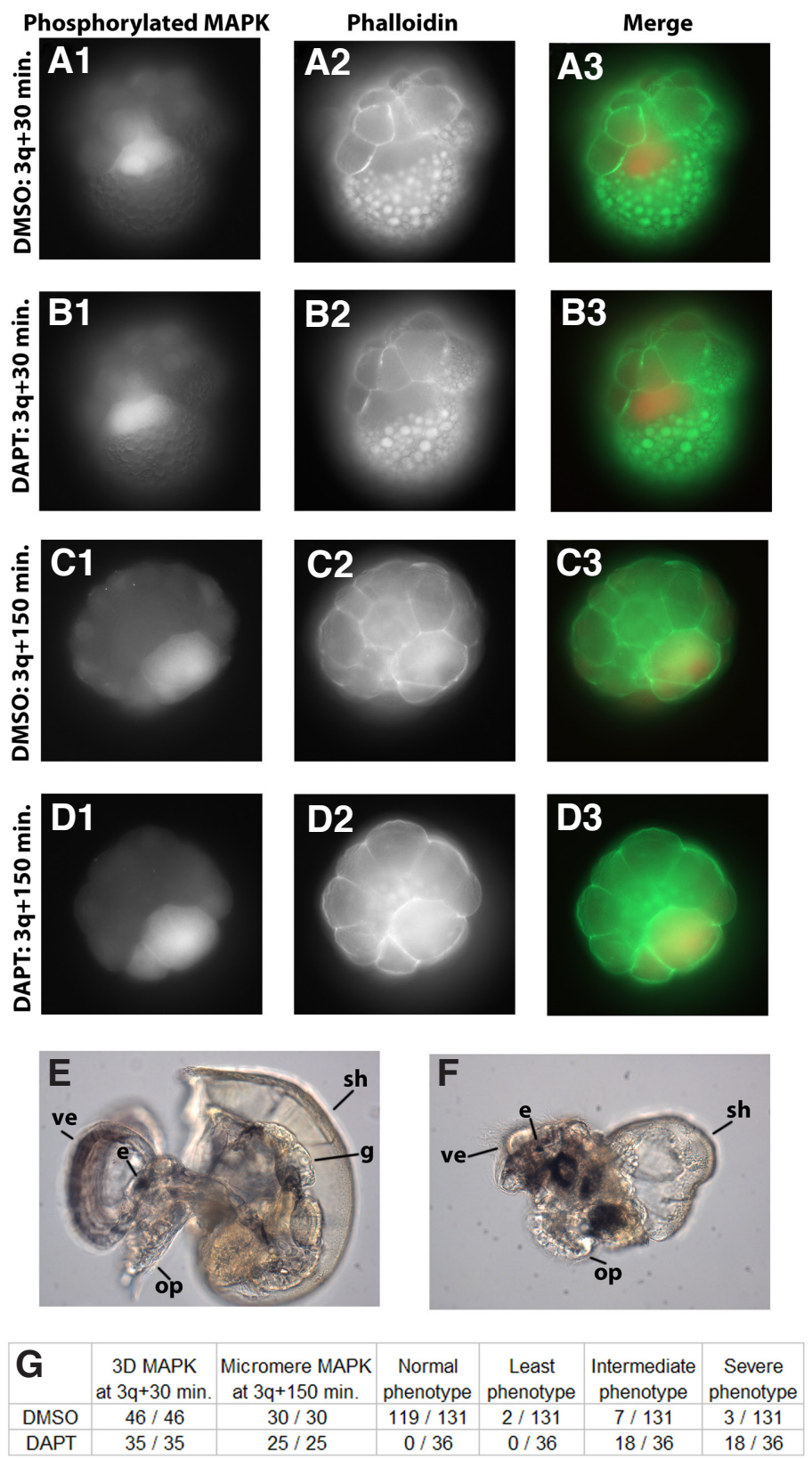

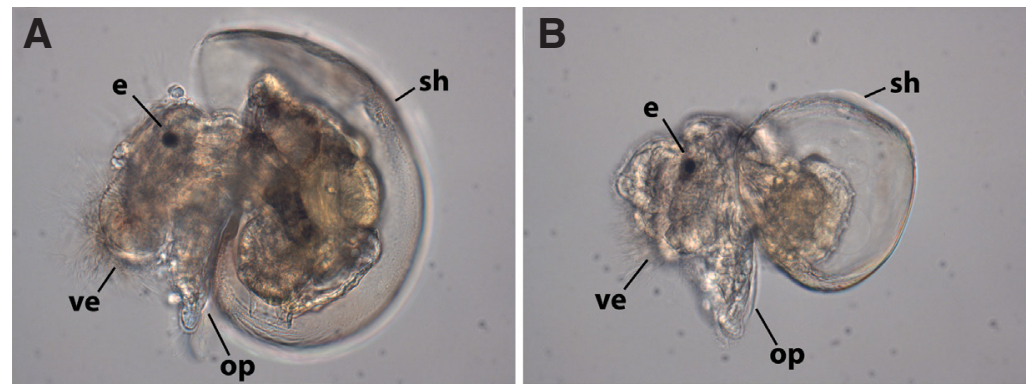

This may be because they were highly disorganized or because their development was delayed or obscured by yolk. Thus, the phenotypes we observe in the DAPT treated embryos resemble loss of $4 d-$ in this case both the loss of inductive signaling from $4 \mathrm{~d}$ (velar, foot, shell defects), as well as the loss of clonal progeny of $4 \mathrm{~d}$. In addition, our results confirm that $4 d$ deletion perturbs endoderm - certainly intestine and style sac, and perhaps stomach and digestive glands as well.

Fig. 6. Loss of 4d signaling mimics DAPT treatment. (A) Control veliger. (B) Veliger resulting from early ( $4 d+20$ minutes) $4 d$ ablation displaying a reduced velum, foot, shell and absent/abnormal internal organ formation. Labeled structures include e, eye, op, operculum, sh, shell, and ve, velum.

DAPT treatment has no consequence on early $4 d$ specification, division, or for the morphogenesis of its clonal derivatives, the larval buds

To determine whether embryonic DAPT treatment affects early $4 \mathrm{~d}$ specification and division, we scored

$(3 q+150$ minutes) and the normal pattern of MAPK activation in the micromeres is thought to reflect micromere fate induction (Fig. 5 C1-C3). To determine whether $\mathrm{N}$ signaling is required for MAPK activation in 3D or the induced micromere cells, we treated embryos at the one cell stage with $25 \mu \mathrm{M}$ DAPT. Embryos were cultured continuously in DAPT until they were fixed at $3 q+30$ minutes and scored for 3D MAPK activation (Fig. 5 B1-3) or fixed at $3 q+150$ minutes and scored for micromere MAPK activation (Fig. 5 D1-3). Both $25 \mu \mathrm{M}$ DAPT treated embryos and sibling control embryos (treated with DMSO alone) displayed a normal pattern of MAPK activation in both the $D$ macromere and the micromeres (3D: DMSO $n=46$ and DAPT $n=35$; micromeres: DMSO $n=30$ and DAPT $n=25$, Fig. 5A-D). Thus, inhibition of $N$ signaling has no consequence on MAPK activation in the early embryo.

\section{Inhibition of $\mathbf{N}$ signaling closely resembles loss of $4 d$}

Veligers resulting from embryonic DAPT treatment and the DI siRNA display a range of defects that are generally less severe than those reported for 3D ablations (which lack both 4d inductive signaling and $4 d$ derivatives). To better characterize the contributions of $4 d$ inductive signaling described in a previous study (Rabinowitz et al., 2008), we ablated 4d from embryos $(n=37)$ shortly after its birth $(4 d+20$ minutes) and scored the resulting veliger phenotypes at 7 days (Fig. 6). These animals had smaller, poorly formed velar lobes, and sometimes lacked one eye. Foot development was also poor in most larvae, and the shell was always smaller than controls. Internal structures were disorganized and yolky compared to controls and often only filled a small portion of the shell behind the head mass. These animals lacked intestines and style sacs. Clement (1986) reported that $4 \mathrm{~d}$ deletions had stomach and digestive glands; these may have been discernable in some of our larva but were never obvious.
DAPT treated embryos for expression of the Ilyanassa Nanos protein that exclusively localizes to $4 \mathrm{~d}$ descendents, as well as 4D (Rabinowitz et al., 2008). Embryos were continuously treated with DAPT (from one cell to $4 d+8$ hours) and scored for localization of Nanos protein in $4 \mathrm{~d}$ descendents. Normal centrosomal Nanos protein localization in two appropriately positioned descendents of $4 \mathrm{~d}$ was observed (4dLm4 and $4 \mathrm{dRm} 4$, using the nomenclature of Lyons et al., 2012; Chan and Lambert, in press; DMSO n=15 and DAPT $n=12$; Fig. 7A,B). Although the division patterns of the $4 \mathrm{~d}$ lineage were not followed, we assume from their proper positioning in the embryo that morphogenesis had proceeded normally to that point in time.

To determine whether embryonic DAPT treatment effects late clonal descendants of $4 \mathrm{~d}$, we used a marker (Stat3 antibody) that exclusively identifies the larval bud cells (Gharbiah, pers. obs.). These cells are sometimes referred to as "larval kidneys" and are difficult, if not impossible, to see in the light microscope in the absence of Stat3 immunohistochemistry. They are $4 \mathrm{~d}$ clonal derivatives (Chan and Lambert, in press). Normal bilateral larval bud development was observed in DMSO and DAPT treated embryos treated for the first 24 hours of development and scored at day 5 of development (DMSO $n=30$ and DAPT $n=26$; Fig. $7 C, D$ ). Typically, DAPT treatment during this time period (see below) results in $28 \%$ severe phenotypes, which have very poorly differentiated internal tissues. That $100 \%$ of the early veligers had larval buds detectable by Stat3 expression was somewhat surprising. These structures lie anterior to most internal organs; perhaps these larval buds develop from a $4 d$ sub-lineage that does not depend on $\mathrm{N}$ signaling for normal development. These data suggest that $\mathrm{N}$ signaling has no consequence on early $4 \mathrm{~d}$ specification, early $4 \mathrm{~d}$ division, or the normal morphogenesis of at least one of the $4 \mathrm{~d}$ clonal derivatives when scored at 5 days.
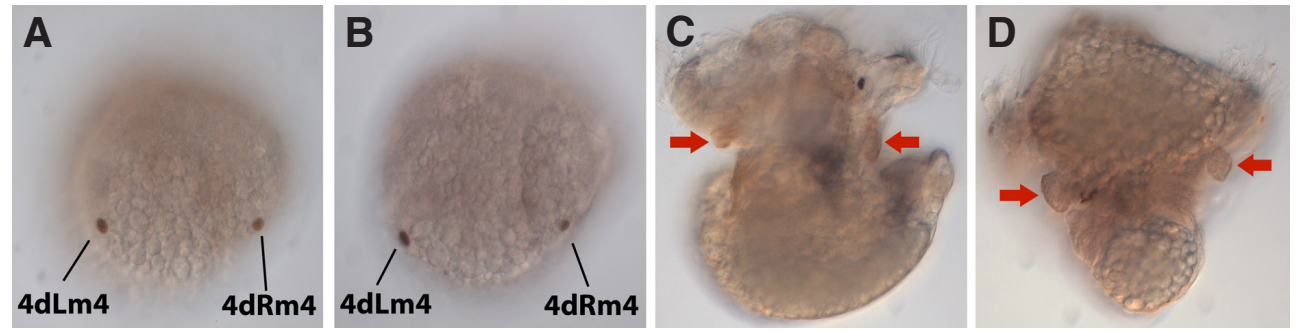

Fig. 7. $\mathrm{N}$ signaling has no consequence on early $4 \mathrm{~d}$ specification, division or morphology of its late clonal derivatives, the larval kidneys. (A,B) loNanos localization via antigen staining in embryos treated with DMSO (A) or DAPT (B) from one cell to $4 d+8$ hours. IoNanos expression is shown localized to nucleus of $4 \mathrm{dLm} 4$ and $4 \mathrm{dRm} 4$ cells. (C,D) Stat3 antigen localization to the larval buds ("larval kidneys") used as marker for $4 d$ clonal derivative morphogenesis. (C) Normal bilateral bud formation in larvae scored on day 5 after DMSO treatment for the first 24hpt. (D) Normal bilateral bud formation in larvae scored on day 5 after DAPT treatment for the first 24 hpt. 

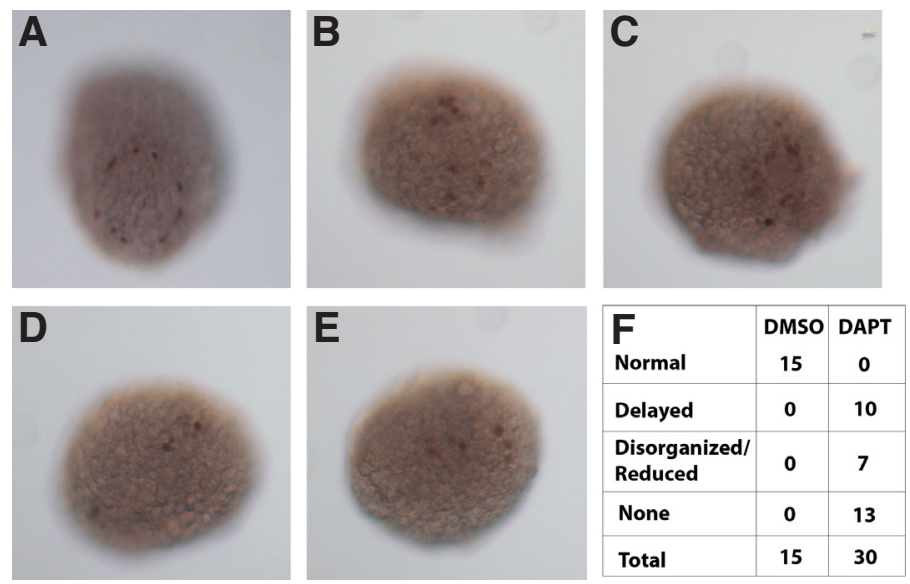

Fig. 8. $\mathbf{N}$ signaling is required for proper shell gland specification. Engrailed protein exclusively localizes to the shell gland and shell gland precursor cells. (A) Four day old DMSO treated control embryo. Circular staining along the shell gland is observed with nine distinct cells staining. (B-E) Four day old embryos, DAPT treated for the first $24 \mathrm{hpt}$, displaying reduced and disorganized engrailed staining. (F) Table comparing results of engrailed staining in DMSO and DAPT treated embryos for the first $24 \mathrm{hpt}$. Scored animals were categorized as either displaying temporally normal EN expression, delayed but normal EN expression, disorganized and/or reduced number of EN expressing cells, or no detectable EN expression in any cell.

\section{N signaling is required for proper shell gland specification}

The shell is significantly affected after DAPT treatment. To determine if inhibition of $\mathrm{N}$ signaling effects early shell fate specification, we used an antibody that detects the Engrailed protein (EN) and scored for proper EN localization in the shell gland of the early larva (Moshel et al., 1998). Normal EN staining begins during the 2nd day of development as two arcs of cells on the right and left sides of the embryo (not shown). As development proceeds, the EN expressing cells migrate closer together to form a horseshoe shape and then enclose to form a circular pattern characteristic of the developing shell gland. By day 4, 9 distinct EN expressing cells in the shell gland are easily recognized (Fig. $8 \mathrm{~A}$ ). Embryos were treated with DAPT for the first 24 hours of development and scored for EN expression at day 4 when the shell gland is most prominent. Control veligers resulting from embryonic DMSO treatment consistently displayed a staining pattern of nine cells in the expected circular pattern along the shell gland field $(n=15 ;$ Fig. 8A). Veligers resulting from embryonic DAPT treatment displayed a range of defects in EN staining (Fig. 8B-E): $33.3 \%$ of treated larvae displayed a developmentally delayed horseshoe shaped staining pattern observed in normal younger larvae $(n=10), 23.3 \%$ of treated larvae display disorganized, scattered pattern of staining with fewer cells $(n=7)$, and $43.3 \%$ of treated larvae display no staining at all $(n=13)$. None of the DAPT veligers displayed a temporally normal staining pattern relative to controls. Thus, shell field specification, is delayed and abnormal in DAPT treated embryos.

\section{Injection of IODI siRNA generates phenotypes similar to DAPT treatment}

To further test the requirement of N-DI signaling, we tested whether injection of IoDI siRNA would mimic the DAPT treatments. $90 \mathrm{uM}$ IoDI siRNA was injected at the 1-cell stage and the embryos were incubated for 7 days (Fig. 9; $n=13$ ). Injection of $20 \mu \mathrm{M}$ loDI siRNA injection had no detectable effect (not shown). The veligers resulting from IoDI siRNA had a range of phenotypes similar to those treated with DAPT (Fig. 9; n=10/13). Posterior structures such as shell, gut, intestine were disorganized or severely reduced. More anterior tissues such as the velum, eyes, foot, and operculum were normal in these embryos. The defects in more anterior structures observed in the most severely affected larvae in the DAPT treatments were not observed in these IoDI siRNA injected veligers (compare Fig. 5F to Fig. 9). Embryos injected with a standard negative control dsRNA (Life Technologies) developed normally $(n=9 / 9)$.

\section{$N$ signaling is required throughout development for the proper morphogenesis of the veliger}

To determine if the phenotype observed in veligers resulting from DAPT embryonic treatment was due to inhibition of $\mathrm{N}$ signaling during particular developmental periods, we treated embryos/ larvae at successive time points during development for 24-hour periods. A total of 28 capsules were treated; 3-5 capsules per each $24 \mathrm{hr}$ treatment. Normal development of the embryo proceeds through completion of cleavage and epiboly at the end of day 1 , gastrulation is primarily complete by day 2 , although the blastopore is not fully closed until day 4 , and organogenesis is ongoing between days 3-7 (Fig. 1;Tomlinson, 1987; Goulding, 2009; Chan and Lambert, 2014).

We found that the highest occurrence of the severe phenotype corresponds to DAPT treatment on the second day of development

Phenotypes of siRNA injection

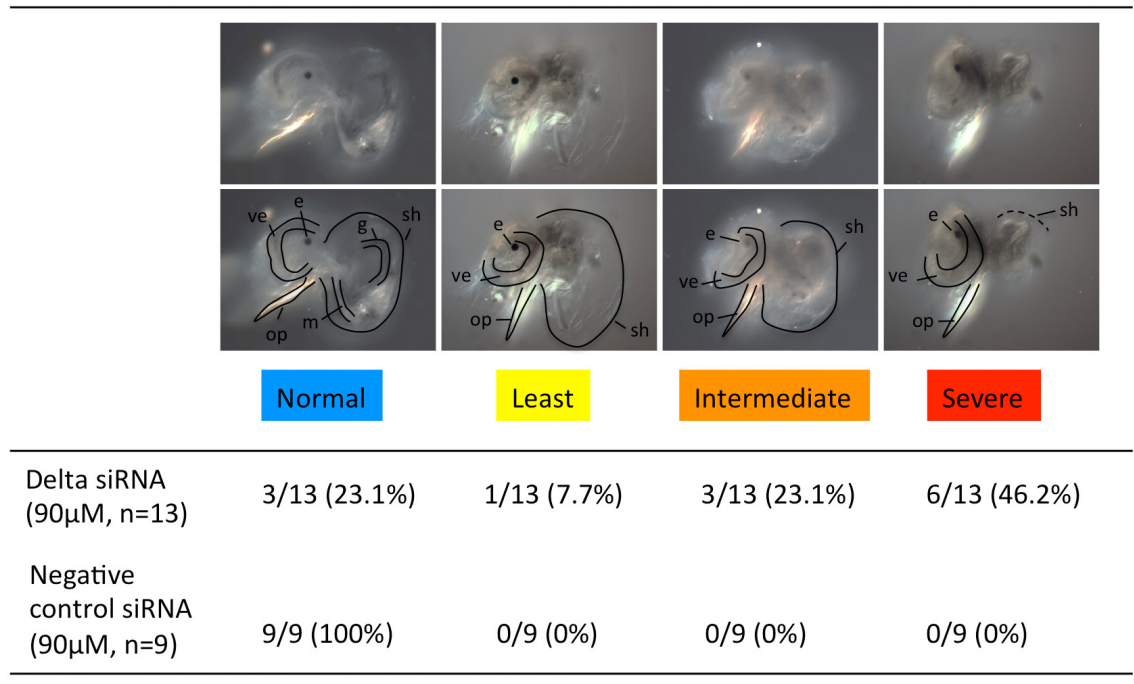

Fig. 9. Phenotypes resulting from IoDI siDI injections. siDI injected into 1 cell zygotes resulted in a range of phenotypes resembling the DAPT treated embryos. Representative larvae from each category are shown; the structures scored in these embryos are highlighted in the lower of the two panels. e, eye; g, gut; $m$, retractor muscle; op, operculum; sh, shell; ve, velum. In severe phenotype, the shell is partially formed (indicated with broken line). Embryos injected with control siRNA developed normally. 
Fig. 10. Successive 24 hour DAPT treatments throughout the development of Ilyanassa. (A) Control veliger, DMSO treated. (B) DAPT treated veliger displaying a "least" phenotype: Normal shell, velum, and foot but severely affected endodermally derived internal organs. (C) DAPT treated veliger displaying an "intermediate" phenotype: Severely affected internal organs as well as reduced velum, foot, and cup-like shell. (D) DAPT treated veliger displaying a "severe" phenotype: Severely affected internal organs, reduced velum and foot, and absent shell. (E) Chart displaying successive DAPT treatment results as percentages of veligers displaying normal (blue), least (yellow), intermediate (orange), and severe (red) phenotypes. Above the chart are cartoon images of larval stages at the end of day 1-7. Cleavage and epiboly are largely complete by the end of day 1. Gastrulation is nearly complete by the end of day 2 and organogenesis is ongoing through day 7. (F) Table of the results displayed in E. Animals were incubated in DAPT for 24 hour periods throughout development. For example, Day 1 treated embryos were incubated in DAPT for 24 hours after trefoil, washed and raised in FASW and scored after nine days of development. Day 2 treated embryos were raised in FASW until 24 hours after trefoil after which they were incubated in DAPT for 24 hours, washed and then raised in FASW and scored after nine days of development. Day 3, 4, 5, 6, and 7 treatments were performed similarly.

(41\%, n=110; Fig. 10). We expect, but cannot be sure (see discussion) that this is beyond the period when $4 d$ is required for organizerdependent cell fates (but perhaps not for signaling from particular $4 \mathrm{~d}$ sub-lineages). The second highest occurrence of the severe phenotypes corresponds to DAPT treatment during the first day of development $(28 \%, n=71$; Fig. 10$)$ that overlaps with a well-established period of $3 \mathrm{D} / 4 \mathrm{~d}$ inductive signaling, and most of the teloblastic divisions of $4 d$ that generate the sub-lineages. Additionally, we found that the highest occurrence of the intermediate phenotype corresponds to DAPT treatment on the fourth and fifth day of development $(59 \%$, $\mathrm{n}=75$ and $65 \%, \mathrm{n}=187$; Fig. 10) during organogenesis. Treatment after five days of development results in greater than two-thirds recovery of the normal veliger phenotype (day $6: 64 \%, n=176$ and day $7: 81 \%, n=182$; Fig. 10$)$. This suggests that either $N$ signaling is required continuously through the first five days of development, or is required for sequential signaling events that have similar phenotypic results.

\section{Discussion}

\section{Expression patterns of $\mathrm{N}, \mathrm{DI}, \mathrm{SuH}$}

Because of the complexity of mechanisms that regulate $\mathrm{N}$ signaling (Dominquez 2014; Hori et al., 2013), inferring function for $\mathrm{N}$ signaling from transcript expression patterns is risky. For example, $\mathrm{N}$ can receive signals from adjacent cells, or from signals on the same cell. SuH can act as a repressor of $\mathrm{N}$ target genes prior to $\mathrm{N}$ signaling, and switch to an activator on receipt of signal. In addition, there are N targets that don't depend on SuH activity. Nonetheless,
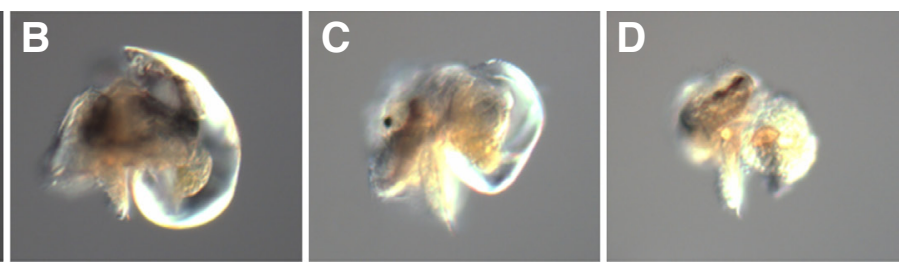

Organogenesis
Day 3 Day 4
Day 5
Day 6 Day 7
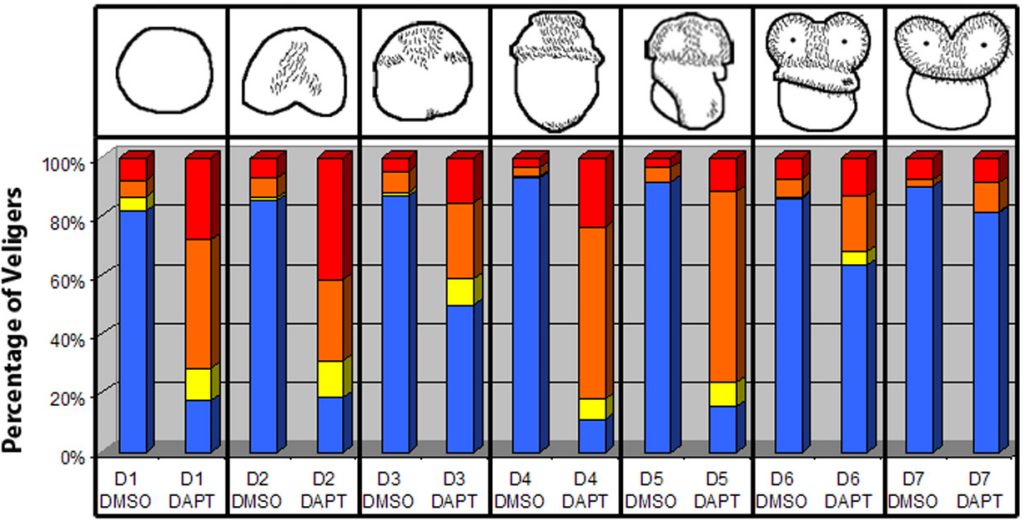

Developmental Day of Treatment

\begin{tabular}{|c|l|c|c|c|c|c|}
\hline \multicolumn{2}{|c|}{} & Normal & Least & Intermediate & Severe & Total \\
\hline \multirow{2}{*}{ Day 1} & DMSO & $205(82 \%)$ & $12(5 \%)$ & $14(6 \%)$ & $19(8 \%)$ & 250 \\
\cline { 2 - 7 } & DAPT & $45(18 \%)$ & $28(11 \%)$ & $112(44 \%)$ & $71(28 \%)$ & 256 \\
\hline \multirow{2}{*}{ Day 2 } & DMSO & $255(86 \%)$ & $2(1 \%)$ & $21(7 \%)$ & $20(7 \%)$ & 298 \\
\cline { 2 - 7 } & DAPT & $50(19 \%)$ & $33(12 \%)$ & $75(28 \%)$ & $110(41 \%)$ & 268 \\
\hline \multirow{2}{*}{ Day 3 } & DMSO & $201(87 \%)$ & $3(1 \%)$ & $16(7 \%)$ & $11(5 \%)$ & 231 \\
\cline { 2 - 7 } & DAPT & $88(50 \%)$ & $16(9 \%)$ & $45(26 \%)$ & $27(15 \%)$ & 176 \\
\hline \multirow{2}{*}{ Day 4 } & DMSO & $191(93 \%)$ & $1(1 \%)$ & $6(3 \%)$ & $7(3 \%)$ & 205 \\
\cline { 2 - 7 } & DAPT & $14(11 \%)$ & $9(7 \%)$ & $75(59 \%)$ & $30(23 \%)$ & 128 \\
\hline \multirow{2}{*}{ Day 5 } & DMSO & $285(92 \%)$ & $0(0 \%)$ & $15(5 \%)$ & $11(4 \%)$ & 311 \\
\cline { 2 - 7 } & DAPT & $45(16 \%)$ & $24(8 \%)$ & $187(65 \%)$ & $33(11 \%)$ & 289 \\
\hline \multirow{2}{*}{ Day 6 } & DMSO & $348(86 \%)$ & $2(1 \%)$ & $25(6 \%)$ & $29(7 \%)$ & 404 \\
\cline { 2 - 7 } & DAPT & $176(64 \%)$ & $13(5 \%)$ & $52(19 \%)$ & $36(13 \%)$ & 277 \\
\hline \multirow{2}{*}{ Day 7 } & DMSO & $195(90 \%)$ & $0(0 \%)$ & $5(2 \%)$ & $16(7 \%)$ & 216 \\
\cline { 2 - 7 } & DAPT & $182(81 \%)$ & $1(0 \%)$ & $22(10 \%)$ & $19(9 \%)$ & 224 \\
\hline
\end{tabular}

when expression patterns are correlated with functional studies, the temporal and spatial patterns of expression have the potential to direct our understanding of N-DI signaling. In particular, lack of expression in a critical lineage or timepoint could eliminate a proposed function. In the early cleavage stages, $I o \mathrm{~N}$ and $l o \mathrm{DI}$ transcripts are ubiquitously but non-uniformly expressed, and undergo dynamic intracellular changes in expression of unknown significance (Fig. 3). Consistent with a functional role of the endoderm in signaling and/ or signal reception, both $\mathrm{IODI}$ and $\mathrm{IOSuH}$ are expressed in some or all of the macromeres throughout the early cleavage stages (Fig. 3). At later cleavage stages, IoN remains ubiquitous (although not uniform) and $l o D I$ is expressed in the daughters of $4 \mathrm{~d}$, as well as on the centrosomes of the $3 \mathrm{~A}, 3 \mathrm{~B}$ and $3 \mathrm{C}$ macromeres (Fig. 4). IoSuH transcripts are primarily expressed in the $4 \mathrm{~d}$ lineage, as well as the macromere 4D (Fig. 4). Because the DAPT treatments and the IoDI siRNA injections mimic loss of $4 \mathrm{~d}$, the observed loSuH expression patterns in particular suggest a role for N-DI signaling in development of the $4 \mathrm{~d}$ lineage, but the expression pattern is also consistent with roles for $\mathrm{N}$ in $4 \mathrm{~d}$ signaling, endoderm specification and/or endoderm signaling. A role for $\mathrm{N}$ and/or $\mathrm{DI}$ in other local signaling events that are less well characterized and potentially obscured in the phenotypes reported here is also possible. 


\section{DAPT treatment affects endoderm formation and cell fates induced by $3 D / 4 d$}

Veligers resulting from either embryonic DAPT treatment or DI siRNA show a range of phenotypes. The least severe phenotypes primarily show defects in endoderm. As the severity progresses, the phenotypes also include reduced and ultimately missing shell, reduced velum, reduced foot, and disorganized or missing internal organs mimicking a $4 \mathrm{~d}$ deletion. Because MAPK expression is initially normal in all the micromeres, we propose that the initial specification of micromere fate by $3 \mathrm{D} / 4 \mathrm{~d}$ is normal, but these cells fail to maintain their fates later in development. However, it is also possible that MAPK is only indicative of one of multiple signaling pathways that induce micromere cell fate, and that micromeres require a $\mathrm{N}$ dependent signal from $3 \mathrm{D} / 4 \mathrm{~d}$ or that $3 \mathrm{D} / 4 \mathrm{~d}$ require a $\mathrm{N}$ dependent inductive signal from the micromeres.

\section{Injection of IODI siRNA results in similar phenotypes to DAPT exposure}

Injection of IoDI siRNA resulted in veligers with primarily posterior defects, including reduction in the size of the shell, missing endoderm and disorganized intestine (Fig. 9). Although we did not directly test for the reduction of IoDI mRNA, with the exception of the most severe phenotype, IoDI siRNA treatment mimicked the effects of the DAPT treatment. Given that the two independent approaches resulted in very similar outcomes, it is reasonable to consider that the IoDI siRNA is effecting the same pathway as DAPT. The absence of the most severe phenotypes in the IoDI siRNA could be due to a failure in the IoDI siRNA to block IoDI expression completely, persistent maternal protein not affected by the siRNA (consistent with the abundant early expression of $/ o \mathrm{~N} / \mathrm{DI}$ mRNA), alternative proteins, e.g. Serrate or other non-canonical N ligands functioning in some of the cellular interactions affected by inhibiting $\gamma$-secretase, or off target effects of DAPT. Delta is also known to function independently of Notch (Mok and Quinn, 2005). Nonetheless, the results suggest that shell and endoderm are the most sensitive to reduction in $\mathrm{N}-\mathrm{DI}$ signaling.

\section{$N$ signaling is likely required throughout development}

Successive 24 hour treatments with DAPT revealed additional requirements for $\mathrm{N}$ signaling beyond the cleavage stages when $4 \mathrm{~d}$ inductive signaling has been documented (Fig. 10). The most frequent occurrence of the severe phenotype corresponds to DAPT treatment on the second day of development $(41 \%)$ followed by the first day of development (28\%) (Fig. 10). Additionally, the successive treatments revealed a continued requirement for $\mathrm{N}$ signaling through the fifth day of development (Fig. 10). These results suggest pleiotropic functions for $\mathrm{N}$ signaling, similar to that observed in other metazoan animals (reviewed in Louvi and Artavanis-Tsakonas, 2012).

Is the $4 d$ lineage itself disrupted by inhibition of $N / D$ Isignaling?

Nanos expression, which marks the early $4 \mathrm{~d}$ lineage, is normal in DAPT treated embryos, suggesting that the specification of $4 \mathrm{~d}$ itself does not require $\mathrm{N}$ signaling (Fig. 7). Later differentiation of the intestine and larval buds suggest that at least some $4 \mathrm{~d}$ derivatives also develop normally (Fig. 7). However, more severe DAPT phenotypes mimic the results of $4 \mathrm{~d}$ ablation (Fig. 5F, 6, 10 , see also Rabinowitz et al., 2008). This phenotype reflects not only defects in other micromere lineages that require signaling from $4 d$ but could also result from a failure to differentiate structures clonally derived from 4 d (Fig. 6, Fig. 7). 4d clonal derivatives might not specified properly, or initially specified but not maintained later in development. Additional markers for the various lineages of $4 \mathrm{~d}$ would be required to determine the degree to which the complete $4 d$ lineage is affected in DAPT treatments.

\section{$N$ signaling is not required for MAPK activation in $3 D$ or in induced micromeres}

The interactions between the polar lobe containing $D$ lineage in Ilyanassa and other cells in the early embryo resemble inhibitory interactions between equivalence groups regulated by $\mathrm{N}$ signaling in other embryos (Artavanis-Tsakonas et al.1994, Campos-Ortega, 1995). Consequently, we hypothesized a role for $\mathrm{N}$ signaling in the activation of the dorsal lineage (3D and $4 d$ ). To test this, we used activated MAPK in 3D, which is subsequently inherited by $4 \mathrm{~d}$, as a marker of active dorsal lineage induction. We found that inhibition of $\mathrm{N}$ signaling through pharmacological drug inhibition (DAPT) had no consequence on MAPK activation in $3 \mathrm{D}$ or on MAPK activation in the induced micromeres. This suggests that $\mathrm{N}$ signaling is not required either to transduce the micromere signal to activate MAPK in 3D or to transduce the 3D/4d inductive signal to activate MAPK in the micromeres (Fig. 5).

\section{$N$ signaling is required for shell gland specification}

Larvae resulting from DAPT treatment displayed a range of EN defects including developmentally delayed but normal EN expression, scattered expression with fewer cells staining for EN, or no EN staining at all (Fig. 8). This suggests that shell gland specification either initially requires $\mathrm{N}$ signaling, or requires $\mathrm{N}$ signaling for its maintenance and proper morphogenesis. The cells in the shell field are clonal descendants of all of the 2 nd quartet cells (Cather, 1967; Render, 1997; Gharbiah et al., 2013;Chan and Lambert, in press) and the shell is missing in 3D deletions (Clement, 1962) and reduced in deletions of $4 d$ (Rabinowitz et al., 2008). Thus, failure to appropriately specify the shell field in the DAPT treated animals could either result from a failure to properly specify the 2 nd quartet cells or a failure to maintain their specification at a later time.

\section{Specification of the endoderm - is $4 d$ involved?}

There is little in the spiralian embryology literature that directly addresses the mechanisms by which endoderm is specified. The macromeres $4 A, B, C$ give rise to the stomach, style sacs and digestive glands (Chan and Lambert, in press), while 4D fate maps to cells in the digestive lumen (Render, 1977). 4a, 4b, and 4c contribute to the digestive glands (Chan and Lambert, in press). Clement (1962) reported that deletions of 3D/4d are missing style sacs (of $3 \mathrm{C}$ origin) and have severely misshapen digestive glands and stomach. The missing style sac was interpreted as lack of permissive growth conditions due to the loss of the intestine, rather than a requirement for an inductive signal from 3D/4d (Render, 1997). The 4d deletions reported here also have missing style sacs, and have more severe internal organ defects than previously reported (Clement, 1962; Rabinowitz et al., 2008). In the leech and Tubifex, $4 \mathrm{~d}$ or $\mathrm{M}$ teloblast ablation disrupts endoderm segmentation and gut differentiation (Gline et al., 2011). Do llyanassa endoderm precursors require a signal from $3 \mathrm{D} / 4 \mathrm{~d}$ to differentiate as endoderm? If so, the signal is likely independent of the proposed organizer signal that activates MAPK in the micromeres, as MAPK 


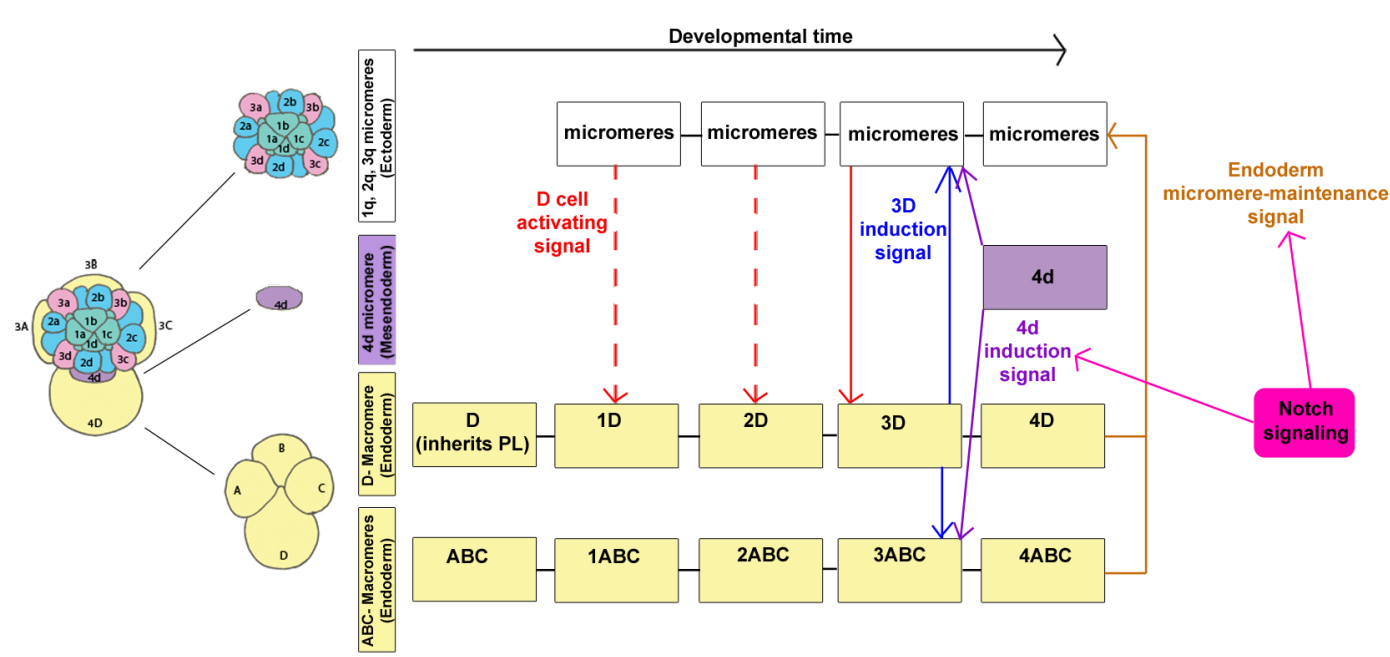

Fig. 11. Model for cell fate determination in Ilyanassa. The $D$ macromere exclusively inherits the polar lobe. Micromere activation of the $D$ cell's inductive abilities (red) is completed soon after the birth of 3D. The precise onset of this signal is not known (dashed red lines). 3D induces polar lobe dependent cell fate specification in the micromeres and other macromeres (b/ue). 3D gives rise to $4 d$ and $4 D$ after which the $D$ macromere induction is complete. $4 d$ continues to induce micromere cell fates (purple). The abnormal endoderm and loss of style sac from 3D/4d deletions (Clement 1967; this report) could indicate a signal from 3D/4d to the endoderm, at least to $3 \mathrm{C}$ (purple). The endoderm is required to maintain induced cell fates after the completion of $D$ lineage cell fate induction (brown) (Cather, 1967). We propose that $N$ signaling (pink box) is involved in 3D/4d induction of cell fates (purple) and in a signaling event between the endoderm and the induced micromeres (brown). Additional functions of $N$ are likely and are not depicted in this diagram.

expression is not detectable in any of the macromeres after the birth of 4d (Lambert and Nagy, 2001). A common defect observed in veligers resulting from DAPT treatment and DI siRNA is absent or abnormal endoderm formation. We propose that N-DI signaling could function as a lateral signal from $3 \mathrm{D} / 4 \mathrm{~d}$ to induce endodermal patterning. In sea urchins, endomesoderm is initially specified by maternalWnt (Wikramanayake etal., 2004). $\beta$-catenin subsequently induces the expression of DI, in the presumptive endoderm, which in turn activates the $\mathrm{N}$ signaling pathways in the neighboring presumptive mesoderm cells. This inhibits Wnt signaling and induces the mesodermal specification program. In the mollusc Crepidula, $\beta$-catenin is selectively stabilized in $4 \mathrm{~d}$ sub-lineages, but knockdown blocks all differentiation in the embryo (Henry et al., 2010). We find that early pharmacological stimulation of Wnt signaling with azakenpaullone results in similar "floating head" phenotypes described here for inhibiting $\mathrm{N}$ signaling (Harrison, Nakamoto and Nagy, pers. obs). Thus, a N-Wnt signaling interaction may share a functional role in endodermal patterning between some spiralian embryos and echinoderm embryos.

\section{IoN/DI signaling may be involved in a signaling event between the endoderm and the micromeres}

The requirement for N/DI signaling during the second day of development could be a result of defects in specification or signaling from $4 \mathrm{~d}$ sublineages. Alternatively, (or in addition) N/DI signaling could be required to maintain $3 D / 4 d$ induced fates (see Fig. 11). We suggest that our data implicates N/DI signaling in both the initial induction of endoderm and the endoderm (3ABCD) may subsequently signal via N/DI to the micromeres to maintain $3 \mathrm{D} / 4 \mathrm{~d}$ cell fate induction. A requirement for endodermal signaling in the maintenance of induced fates closely overlapping this period has been previously implicated in the Ilyanassa literature. Cather (1967) reported that the removal of the endoderm (3ABCD which contribute to the digestive glands, velar retractor, style sac, intestine, heart, kidney (Render, 1997)) resulted in animals that failed to differentiate 3D induced fates. Cather reported that these animals formed into hollow ball-like animals that developed cilia but did not differentiate any other discernable larval structure. While this result in itself is not surprising, given the known role for $3 \mathrm{D}$, retention of any endoderm forming cell (3A, 3B, 3C or 3D), not just the expected $3 \mathrm{D}$, resulted in veligers which could achieve fairly good morphology of eyes, velum, foot, and sometimes shell which are structures known to be effected in 3D ablations. Even more surprising, removal of the single remaining endoderm precursor (in this particular study, 3C) more than 16 hours after the birth of $4 d$ in the controls resulted in a loss of cell fate induction. These experiments resulted in animals that were hollow ball-like animals with no shell, foot, or other notable structures and were identical to the animals in which the entire endoderm was removed at once $(3 A B C D)$ and removed much earlier in development. Additionally, removal of the endoderm 40 minutes after the birth of $4 \mathrm{~d}$ (3ABC4D) resulted in a loss of cell fate induction (Cather, 1967). Scoring the DAPT treated embryos for endoderm specific markers would further substantiate this model.

\section{N signaling function within lophotrochozoans}

In Ilyanassa, the data reported above supports a role for $\mathrm{N}$ signaling in maintaining cell fate patterning induced by the $D$ lineage. The only other functional report for $\mathrm{N}$ signaling in a lophotrochozoan is in the leech in which $\mathrm{N}$ signaling was implicated in segmental induction by $D$ lineage cells (Rivera and Weisblat, 2008). If $N$ is required to specify $4 \mathrm{~d}$ fates, then in both species it is involved in patterning posterior teloblastic lineages. The requirement for endodermal patterning we report here is not shared with the leech, and suggests that 1) $\mathrm{N}$ signaling has evolved independent functions in derived annelids and derived molluscs, or 2) N signaling plays an important role in endodermal patterning and $D$ lineage signaling in both annelids and molluscs, but the morphological consequence of this signaling has diverged with time.

\section{Evolution of the role of $\mathbf{N}$ signaling within metazoans}

The discovery that $\mathrm{N}$ signaling is required for segmentation in annelids, arthropods and vertebrates has increased speculation regarding the evolutionary origins of segmented body plans in metazoans (Erwin and Davidson 2002; Seaver, 2003; De Robertis 2008; Couso 2009; Rivera and Weisblat, 2009, Chipman 2010; Williams 
et al., 2012; Erickson et al., 2013). As the molluscan 4d lineage is related to teloblastic growth and by extension segmentation, a role for $\mathrm{N}$ signaling in the molluscan $\mathrm{D}$ lineage is relevant to these arguments. There are two major, competing hypotheses as to the origin of segmentation (see references above, as well as Balavoine, this issue): 1) a single origin of segmentation in metazoan animals with a single, segmented ancestral bilaterian; 2) multiple origins of segmentation in which all three clades independently evolved segmented animals. The argument for a single origin is supported by the requirement for $\mathrm{N}$ signaling in segmentation of representative animals from all three clades of segmented metazoans. However, within each clade of segmented animals there are numerous examples of closely related segmented and unsegmented animals. This suggests that segmentation has been lost numerous times throughout evolution or that $\mathrm{N}$ signaling has been independently recruited at least three times to function in segmentation. We found that $\mathrm{N}$ signaling in non-segmented animals such as the mollusc Ilyanassa has a potential role in the $4 \mathrm{~d}$ lineage, known for its teloblastic growth - a mechanism shared with segmental growth in annelids. We also present evidence for a role for $\mathrm{N}$ in the function of the endodermal lineage in Ilyanassa - a $\mathrm{N}$ function shared with echinoderms - another non-segmented clade of animals. Loss of $\mathrm{N}$ signaling also affects the patterning of multiple cell fates including a uniquely molluscan feature, the shell. Additional sampling of other lophotrochozoans and unsegmented animals will help clarify the evolution of $\mathrm{N}$ signaling within the Metazoa.

\section{Materials and Methods}

\section{Snail husbandry}

Adult snails were obtained from the Marine Resources Center at the Marine Biological Laboratory (Woods Hole, MA) or collected from Bar Harbor, Maine or from Roberts Landing in Alameda County, California. Adult snails were maintained and embryos collected and reared as previously described (Gharbiah et al., 2009). Time of development was scored as hours post-trefoil (hpt) at room temperature, the stage of early embryogenesis between first and second cleavage when the large polar lobe is fully extruded (Tomlinson, 1987).

\section{Cloning, orthology assignments and sequence alignments}

$I O N$ and $I O D I$ cDNAs were cloned by polymerase chain reaction (PCR) with degenerate primers from cDNA generated from mixed stages. Primer sequences are available upon request. IoSuHcDNAs were cloned by PCR using gene specific primers to EST sequences (Kingsley et al., 2007). in situ hybridizations were carried out as previously described (Lambert and Nagy, 2002). Sequences isolated by degenerate PCR were assigned orthologies based on BLASTX searches of the GenBank database at $\mathrm{NCBI}$. In addition, the llyanassa EST sequences were searched for additional orthologs of N, DI and SuH. Amino acid sequences from mouse, Drosophila, and Lottia were downloaded from the protein database in GenBank. Amino acid sequence alignments were made using ClustalX, using default parameters.

\section{Immunohistochemistry, in situ hybridization}

Immunohistochemistry was performed as described by Lambert and Nagy (2001) with the following alterations: Embryos used for anti-active (double phosphorylated) MAPK antibody (1:200, M8159, Sigma), anti-engrailed (1:1, 4D9, DHSB), and anti-nanos (1:50, Rabinowitz 2009), mouse anti-STAT (Chemicon MAB3705) were fixed for 30 minutes in Pipes-EGTA-Magnesium (PEM) (100 mM PIPES [pH 6.9 ], $10 \mathrm{mM} \mathrm{EGTA}$, and $1 \mathrm{mM} \mathrm{MgSO}_{4}$ ) with $4 \%$ paraformaldehyde and $0.1 \%$ Triton $\mathrm{X}$ at $\mathrm{RT}$.

\section{DAPT drug treatment}

10mM DAPT (N-[N-(3,5-Difluorophenacetyl-L-alanyl)]-S-phenylglycine t-Butyl Ester; Calbiochem) stock in DMSO was stored at $-20^{\circ} \mathrm{C}$. Working concentration of DAPT was diluted in Filtered Artificial Sea Water (FASW) just prior to use. To determine drug concentration for experiments a dose response curve was performed. At concentrations higher than $25 \mathrm{uM}$ more than half of the embryos did not survive to the veliger stage. At lower concentrations, an increasing percentage of the larvae developed normally. Therefore for all drug treatments embryos from the same capsule were incubated in FASW containing either DMSO (2.5\%) or $25 \mu \mathrm{M}$ DAPT (2.5uL of $10 \mathrm{mM}$ DAPT in DMSO/mL of FASW). After drug incubation, embryos were washed three times in FASW and reared in $0.2 \mu \mathrm{m}$-filtered artificial seawater (FASW, Instant Ocean) at RT $\left(21^{\circ} \mathrm{C}\right)$ with penicillin (10 units/ $\mathrm{mL}$ ) and streptomycin $(10 \mu \mathrm{g} / \mathrm{mL})$ (7-9 days). Variation in rate of development both among siblings from the same capsule (small variation) and between capsules (much larger variation) has been noted in the literature (Tomlinson, 1987). Therefore, all 24-hour treatments that involve multiple capsule treatments have approximate start and end times of \pm 6 hours for the stated period of developmental incubation.

\section{Injection of DI dsRNA}

Double-stranded Stealth siRNA (Life Technologies) was used for the DI RNAi experiment. The following sequence (5' to 3') for DI siRNA was designed with BLOCK-IT RNAi program (Life Technologies): GACCAGTGCAAGACCCACTTCAACT. Stealth RNAi siRNA negative control Med GC duplex (Life Technologies, catalog \#12935300) was used as a control. The DI dsRNA and control dsRNA were injected at a concentration of $90 \mu \mathrm{M}$ of dsRNA and $0.5 \%$ tetramethylrhodamine (Fluoro-Ruby) 10,000 MW, lysine-fixable (Life Technologies).

\section{$4 d$ deletions}

$4 \mathrm{~d}$ was ablated by a glass needle roughly 20 minutes following its birth. The cell was removed and the larvae were cultured for 7 days prior to fixation.

\section{Scoring and fixing larvae}

Injected and drug treated embryos were fixed after rearing to veliger stage and most of the internal nutritive yolk had diminished allowing for organ visibility (7-9 days). Veligers were relaxed in a mixture of two parts FASW with one part saturated trichlorobutanol, and then fixed with $3.7 \%$ formaldehyde in FASW for 30 minutes at room temperature and mounted in $80 \%$ glycerol+4\% n-propyl-gallate in PBS.

\section{Acknowledgements}

The authors are grateful to the careful review and suggestions provided by two anonymous reviewers. This work was funded by NSF IOB- 0820564 (LMN) and NSF IOB- 1146782 (JDL).

\section{References}

ARTAVANIS-TSAKONAS S, RAND M D and LAKE R J (1999). Notch signaling: cell fate control and signal integration in development. Science 284: 770-776.

ATKINSON J W (1969). A comparative study of histogenesis and organogenesis in normal and lobeless embryos of the marine prosobranch gastropod, Ilyanassa obsoleta. Vol. PhD. Emory University.

BLAND C E, KIMBERLY P, RAND M D (2003). Notch-induced proteolysis and nuclear localization of the Delta ligand. J Biol Chem 278: 13607-13610.

BRAY S (1998). Notch signalling in Drosophila: three ways to use a pathway. Semin Cell Dev Biol 9: 591-597.

BRAY S J (2006). Notch signalling: a simple pathway becomes complex. Nat. Rev Mol. Cell Biol. 7: 678-689.

CATHER J N (1967). Cellular interactions in the development of the shell gland of the gastropod, Ilyanassa. J Exp Zool 166: 205-223.

CHAN XY, LAMBERT J D (2014). Development of blastomere clones in the llyanassa embryo: transformation of the spiralian blastula into the larval body plan. Dev Genes Evol 224:159-74. 
CHEN J, CRABBE A, VAN DUPPEN V, VANKELECOM H (2006). The Notch signaling system is present in the postnatal pituitary: marked expression and regulatory activity in the newly discovered 'side population'. Mol Endocrinol 20: 3293-3307.

CHIPMAN A D (2010). Parallel evolution of segmentation by co-option of ancestral gene regulatory networks. Bioessays 32: 60-70

CLEMENT A C (1952). Experimental studies on germinal localization in Ilyanassa. I. The role of the polar lobe in determination of the cleavage pattern and its influence in later development. J Exp Zool 121: 593-625.

CLEMENTAC (1962). Development of Ilyanassafollowing removal of the D-macromere at successive cleavage stages. J Exp Zool 149: 193-215.

CLEMENT A C (1986b). The embryonic value of the micromeres in Ilyanassa obsoleta, as determined by deletion experiments. III. The third quartet cells and the mesentoblast cell, 4d. Int J Invertebr Reprod Dev 9: 155-168.

COUSO J P (2009). Segmentation, metamerism and the Cambrian explosion. Int $J$ Dev Biol 53: 1305-1316.

DE ROBERTIS E M (2008). The molecular ancestry of segmentation mechanisms. Proc Natl Acad Sci USA 105: 16411-16412.

DOMINGUEZ M (2014). Oncogenic programmes and Notch activity: An 'organized crime'? Semin Cell Dev Biol 28C: 78-85.

ERIKSSON B J, UNGERER P, STOLLEWERK A. (2013). The function of Notch signalling in segment formation in the crustacean Daphnia magna (Branchiopoda). Dev Biol 383: 321-330.

ERWIN D H, AND DAVIDSON E H (2002). The last common bilaterian ancestor. Development 129: 3021-3032.

FIUZA U M, ARIAS, A M, (2007). Cell and molecular biology of Notch. J Endocrinol 194: 459-474

FUJIMAKI R, TOYAMA Y, HOZUMI N, TEZUKA K (2006). Involvement of Notch signaling in initiation of prechondrogenic condensation and nodule formation in limb bud micromass cultures. J Bone Miner Metab 24: 191-8.

GAL H, AMARIGLIO N, TRAKHTENBROT L, JACOB-HIRSH J, MARGALIT O, AVIGDOR A, NAGLER A, TAVOR S, EIN-DOR L, LAPIDOT T, DOMANY E, RECHAV G, GIVOLD (2006). Gene expression profiles of AML derived stem cells; similarity to hematopoietic stem cells. Leukemia 20: 2147-2154.

GELING A, STEINER H, WILLEM M, BALLY-CUIF L, HAASS C (2002). A gammasecretase inhibitor blocks Notch signaling in vivo and causes a severe neurogenic phenotype in zebrafish. EMBO Rep 3: 688-694.

GHARBIAH M, COOLEY J, LEISE M, NAKAMOTO A, RABINOWITZ J S, LAMBERT J D, NAGY L M(2009). The Snail Ilyanassa: A Reemerging Model for Studies in Development. Emerging Model Organisms: A Laboratory Manual, Volume 1. Cold Spring Harbor Laboratory Press.

GHARBIAH M, NAKAMOTOAN, NAGY LM (2013). Analysis of ciliary band formation in the mollusc Ilyanassa obsoleta. Dev Genes Evol. 223: 225-235.

GOULDING M Q (2009). Cell lineage of the Ilyanassa embryo: evolutionary acceleration of regional differentiation during early development. PLoS One 4: e5506.

GLINE SE, NAKAMOTO A, CHO SJ, CHI C, WEISBLAT DA (2011). Lineage analysis of micromere $4 d$, a super-phylotypic cell for Lophotrochozoa, in the leech Helobdella and the sludgeworm Tubifex. Dev Biol 353: 120-133.

HIRATOCHI M, NAGASE H, KURAMOCHI Y, KOH C S, OHKAWARA T, NAKAYAMA K (2007). The Delta intracellular domain mediates TGF-beta/Activin signaling through binding to Smads and has an important bi-directional function in the Notch-Delta signaling pathway. Nucleic Acids Res. 35: 912-922.

HORI K, SEN A, ARTAVANIS-TSAKONAS S (2013). Notch signaling at a glance. $J$ Cell Sci 2013 126: 2135-2140.

KADESCH T (2004). Notch signaling: the demise of elegant simplicity. Curr Opin Gen Dev 14: 506-512.

KINGSLEY E P, CHAN X Y, DUAN Y, LAMBERT J D (2007). Widespread RNA segregation in a spiralian embryo. Evol Dev 9: 527-539.

KITZMANN M, BONNIEU A, DURET C, VERNUS B, BARRO M, LAOUDJCHENIVESSE D, VERDI J M, CARNAC G (2006). Inhibition of Notch signaling induces myotube hypertrophy by recruiting a subpopulation of reserve cells. $J$ Cell Physiol 208: 538-548.

KIYOTA T, KINOSHITA T (2004). The intracellular domain of X-Serrate-1 is cleaved and suppresses primary neurogenesis in Xenopus laevis. Mech Dev121:573-585.

KOPAN R, ILAGAN M X (2009). The canonical Notch signaling pathway: unfolding the activation mechanism. Cell 137: 216-233.

LAMBERT J D, NAGY L M, (2001). MAPK signaling by the D quadrant embryonic organizer of the mollusc llyanassa obsoleta. Development 128: 45-56.

LAMBERT J D, NAGY L M (2002). Asymmetric inheritance of centrosomally localized mRNAs during embryonic cleavages. Nature 420: 682-686.
LAVOIE M J, SELKOE D J (2003). The Notch ligands, Jagged and Delta, are sequentially processed by alpha-secretase and presenilin/gamma-secretase and release signaling fragments. J Biol Chem 278: 34427-34437.

LI H, YU B, ZHANG Y, PAN Z, XU W, LI H (2006). Jagged1 protein enhances the differentiation of mesenchymal stem cells into cardiomyocytes. Biochem Biophys Res Commun 341: 320-325.

LOUVI A, ARTAVANIS-TSAKONAS, S (2012) Notch and disease: a growing field Semin Cell Dev Biol.23: 473-480.

MICCHELLICA, ESLERWP, KIMBERLYWT, JACKC, BEREZOVSKAO, KORNILOVA A, HYMAN B T, PERRIMON N, WOLFE M S (2003). Gamma-secretase/presenilin inhibitors for Alzheimer's disease phenocopy Notch mutations in Drosophila. FASEB J 17: 79-81.

MOK L P, QIN, T et al., (2005). "Delta activity independent of its activity as a ligand of Notch." BMC Dev Biol 5: 6.

MOSHEL S M, LEVINE M, COLLIER, J R, (1998). Shell differentiation and engrailed expression in the Ilyanassa embryo. Dev Genes Evol 208: 135-41.

MÜNDER S, TISCHER S, GRUNDHUBER M, BÜCHELS N, BRUCKMEIER N, ECKERT S, SEEFELDT CA, PREXL A, KÄSBAUER T, BÖTTGER A., (2013). Notch-signalling is required for head regeneration and tentacle patterning in Hydra. Dev Biol 383: 146-57.

NAKAYAMAK, NAGASE H, HIRATOCHI M, KOH C S, OHKAWARAT (2008). Similar mechanisms regulated by gamma-secretase are involved in both directions of the bi-directional Notch-Delta signaling pathway as well as play a potential role in signaling events involving type 1 transmembrane proteins. Curr Stem Cell Res Ther 3: 288-302.

NICHOLS J T, MIYAMOTO A, WEINMASTER G, (2007). Notch Signaling - Constantly on the Move. Traffic 8: 959-969.

PUEYO J I, LANFEAR R, COUSO J P (2008). Ancestral Notch-mediated segmentation revealed in the cockroach Periplaneta americana. Proc Natl Acad Sci USA 105: 16614-16619.

RABINOWITZ J S, CHAN X Y, KINGSLEY E P, DUAN Y, LAMBERT J D (2008) Nanos is required in somatic blast cell lineages in the posterior of a mollusk embryo. Curr Biol 18, 331-6.

RENDER J (1991). Fate maps of the first quartet micromeres in the gastropod Ilyanassa obsoleta. Development 113: 495-501.

RENDER J (1997). Cell fate maps in the llyanassa obsoleta embryo beyond the third division. Dev Biol 189: 301-10.

RIVERA A S, WEISBLAT D A (2008). And Lophotrochozoa makes three: Notch/Hes signaling in annelid segmentation. Dev Genes Evol 219: 37-43.

SEAVERE C (2003). Segmentation: mono- or polyphyletic? Int J Dev Bio/47:583-595.

SHERWOOD D R, MCCLAY D R (1997). Identification and localization of a sea urchin Notch homologue: insights into vegetal plate regionalization and Notch receptor regulation. Development 124: 3363-3374.

SHERWOOD D R, MCCLAY D R (2001). LvNotch signaling plays a dual role in regulating the position of the ectoderm-endoderm boundary in the sea urchin embryo. Development 128: 2221-2232.

SWEET HC (1996). Regional specification of first quartet micromeres in the embryos of the gastropod Ilyanassa obsoleta. Vol. Ph.D. University of Texas, Austin.

SWEETHC, GEHRING M, ETTENSOHNCA(2002). LvDelta is a mesoderm-inducing signal in the sea urchin embryo and can endow blastomeres with organizer-like properties. Development 129: 1945-1955.

TOMLINSON S G (1987). Intermediate stages in the embryonic development of the gastropod Ilyanassa obsoleta: a scanning electron microscope study. Int J Inver Rep and Dev 253-280.

TSUDA L, NAGARAJ R, ZIPURSKY S L, BANERJEE U (2002). An EGFR/Ebi/Sno pathway promotes delta expression by inactivating $\mathrm{Su}(\mathrm{H}) / \mathrm{SMRTER}$ repression during inductive notch signaling. Cell 110: 625-637.

WANDELT J (2005). Dorsal-Ventral Patterning in the Mud Snail, Ilyanassa obsoleta. Molecular Cellular Biology, Vol. PhD. University of Arizona, Tucson.

WILLIAMS T, BLACHUTA B, HEGNA, TA, NAGY L M (2012). Decoupling elongation and segmentation: notch involvement in anostracan crustacean segmentation. Evol Dev 4: 372-382.

WIKRAMANAYAKEAH, PETERSON R, CHEN J, HUANG L, BINCE, J M, MCCLAY, D R, KLEIN W H (2004). Nuclear beta-catenin-dependent Wnt8 signaling in vegeta cells of the early sea urchin embryo regulates gastrulation and differentiation of endoderm and mesodermal cell lineages. Genesis 39: 194-205.

ZECCHINE, FILIPPIA, BIEMARF, TISON, PAULSS, ELLERTSDOTTIRE, GNUGGE L, BORTOLUSSI M, DRIEVER W, ARGENTON F (2006). Distinct delta and jagged genes control sequential segregation of pancreatic cell types from precursor pools in zebrafish. Dev Biol 301: 192-204. 


\section{Further Related Reading, published previously in the Int. J. Dev. Biol.}

Hydra, a model system to trace the emergence of boundaries in developing eumetazoans Angelika Böttger and Monika Hassel

Int. J. Dev. Biol. (2012) 56: 583-591

Planarian regeneration: a classic topic claiming new attention

Emili Saló and Kiyokazu Agata

Int. J. Dev. Biol. (2012) 56: 1-4

Segmentation, metamerism and the Cambrian explosion

Juan Pablo Couso

Int. J. Dev. Biol. (2009) 53: 1305-1316

A history of Evo-Devo research in Spain

Jaume Baguñà

Int. J. Dev. Biol. (2009) 53: 1205-1217

The first bilaterian organisms: simple or complex? New molecular evidence

J Baguna, I Ruiz-Trillo, J Paps, M Loukota, C Ribera, U Jondelius, M Riutort

Int. J. Dev. Biol. (2001) 45: S133-S134

5 yr ISI Impact Factor $(2011)=2.959$
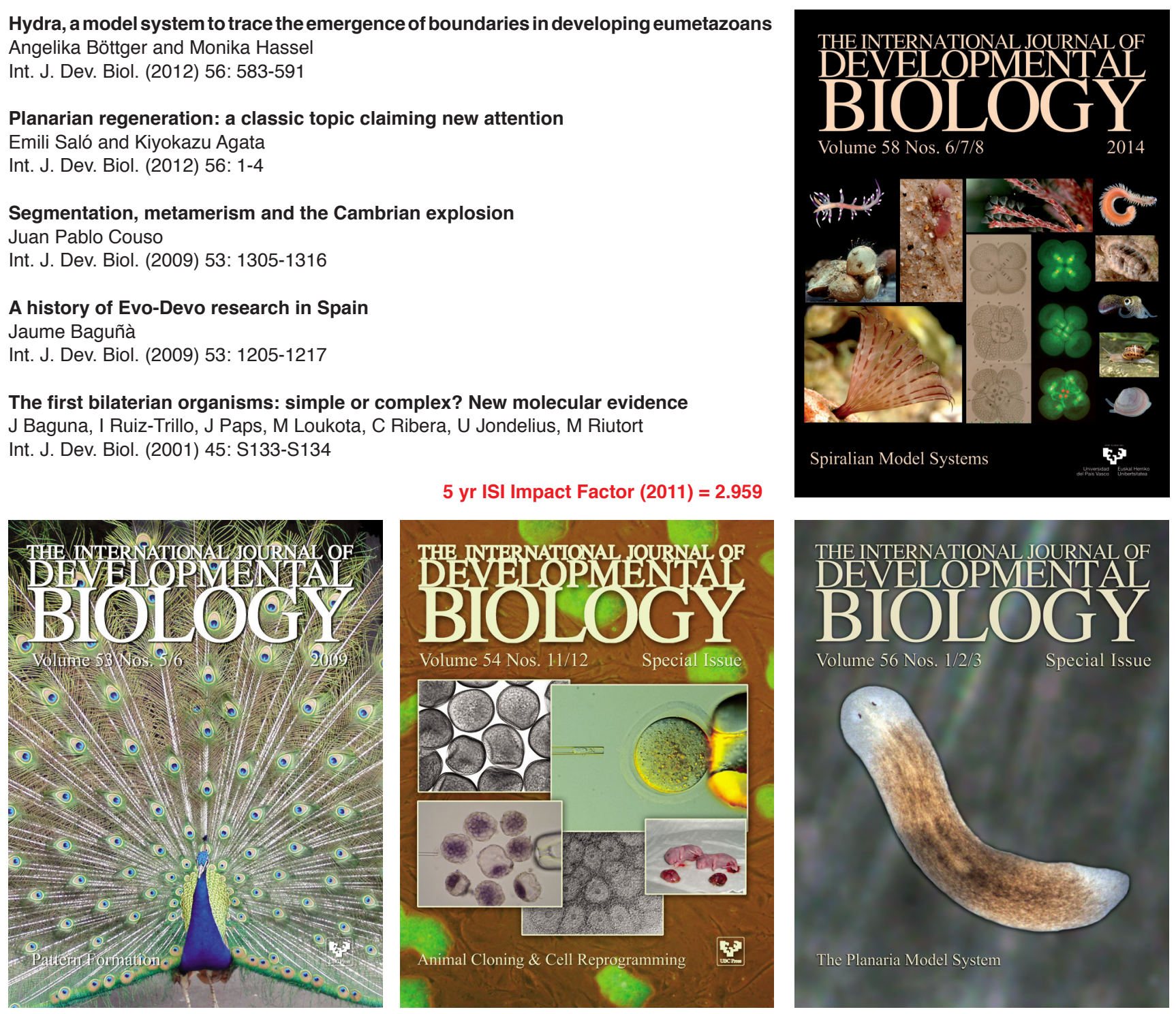